\title{
Evasion of Early Antiviral Responses by Herpes Simplex Viruses
}

\author{
Paula A. Suazo, ${ }^{1}$ Francisco J. Ibañez, ${ }^{1}$ Angello R. Retamal-Díaz, ${ }^{1}$ Marysol V. Paz-Fiblas, ${ }^{1}$ \\ Susan M. Bueno,, ${ }^{1,2}$ Alexis M. Kalergis, ${ }^{1,2,3}$ and Pablo A. González ${ }^{1}$ \\ ${ }^{1}$ Millennium Institute on Immunology and Immunotherapy, Departamento de Genética Molecular y Microbiología, \\ Facultad de Ciencias Biológicas, Pontificia Universidad Católica de Chile, 8331010 Santiago, Chile \\ ${ }^{2}$ INSERM UMR1064, 44093 Nantes, France \\ ${ }^{3}$ Departamento de Inmunología Clínica y Reumatología, Escuela de Medicina, Facultad de Medicina, \\ Pontificia Universidad Católica de Chile, 8331010 Santiago, Chile \\ Correspondence should be addressed to Pablo A. González; pagonzalez@bio.puc.cl
}

Received 12 January 2015; Accepted 10 March 2015

Academic Editor: Marja Ojaniemi

Copyright (C) 2015 Paula A. Suazo et al. This is an open access article distributed under the Creative Commons Attribution License, which permits unrestricted use, distribution, and reproduction in any medium, provided the original work is properly cited.

Besides overcoming physical constraints, such as extreme temperatures, reduced humidity, elevated pressure, and natural predators, human pathogens further need to overcome an arsenal of antimicrobial components evolved by the host to limit infection, replication and optimally, reinfection. Herpes simplex virus-1 (HSV-1) and herpes simplex virus-2 (HSV-2) infect humans at a high frequency and persist within the host for life by establishing latency in neurons. To gain access to these cells, herpes simplex viruses (HSVs) must replicate and block immediate host antiviral responses elicited by epithelial cells and innate immune components early after infection. During these processes, infected and noninfected neighboring cells, as well as tissue-resident and patrolling immune cells, will sense viral components and cell-associated danger signals and secrete soluble mediators. While type-I interferons aim at limiting virus spread, cytokines and chemokines will modulate resident and incoming immune cells. In this paper, we discuss recent findings relative to the early steps taking place during HSV infection and replication. Further, we discuss how HSVs evade detection by host cells and the molecular mechanisms evolved by these viruses to circumvent early antiviral mechanisms, ultimately leading to neuron infection and the establishment of latency.

\section{Introduction}

Herpesviruses are frequently found in humans, although their prevalence significantly varies depending on ethnicity, sex, and geographical location of individuals, among others [1-5]. Currently, eight Herpesviridae family members are known to infect humans: herpes simplex viruses (HSV) -1 and -2 (HSV-1, HHV-1 and HSV-2, HHV-2, resp.), varicella zoster virus (VZV, HHV-3), Epstein Barr (EBV, HHV4), cytomegalovirus (CMV, HHV-5), human herpesvirus 6 (HHV-6), human herpesvirus 7 (HHV-7), and Kaposi sarcoma-associated virus (KSV or HHV-8). All herpesviruses harbor large genomes encoding $>70$ genes and share the capacity to establish lifelong persistent infections in the host ([6] and NCBI).

Human infection with herpes simplex viruses (HSVs) traces far back, even before the intercontinental migration of our ancestors, as proposed by recent phylogenetic analyses [7]. Symptomatic manifestations of HSVs have been described as early as $400 \mathrm{BC}$ and these viruses are often considered the oldest viruses to be studied in the history of science [8]. While HSV-1 is estimated to infect up to one-third of the world population, HSV-2 infects nearly 500 million people around the globe with more than 20 million new cases occurring every year [4]. Importantly, HSV-1 is the foremost important cause of infectious blindness in developed countries and has gained importance in primary genital infection, surpassing in many cases HSV2 [9-22]. Nevertheless, because HSV-2 recurs significantly more often than HSV-1 in the genitalia, HSV-2 remains overall the most frequent cause of genital ulcers worldwide [23-26]. It is important to bear in mind that HSV-1 and HSV-2 also produce several other pathological conditions, such as encephalitis, conjunctivitis, zosteriform skin lesions, 
pneumonia, and systemic infections that compromise vital organs [1]. An important concern regarding genital infection with HSV is its association with increased HIV infection. Indeed, genital infection with HSV has been suggested to increase up to 3-4 times the susceptibility of acquiring HIV [27-29], which has been proposed to be mediated, at least in part by soluble mediators at the infection site $[30,31]$. Furthermore, individuals coinfected with HSV and HIV shed significantly more these viruses than individuals with single viral infections [32-34].

Important efforts have been invested in the past 20 years on the development of a vaccine against HSVs. However, potential vaccine formulations that have reached the clinic have proven ineffective at preventing infection or reducing virus shedding $[35,36]$. Discouraging results derived from the latest HSV-2 vaccine clinical trial, which used a viral subunit formulation, have led to new debates in the field and rethinking on the role of neutralizing antibodies in protecting against HSV-2, as well as the need for correlates of protection [37-39]. Indeed, somewhat unexpected results were obtained with a subunit vaccine consisting of HSV-2 glycoprotein D (gD) plus an adjuvant, which was found to be more efficacious against $\mathrm{HSV}-1$ than against HSV-2-induced genital disease $[40,41]$. Again, these data are leading to new paradigm shifts in the field that hopefully will translate into novel vaccine approaches that could eventually reach the clinic. The lack of an effective vaccine against HSVs has flourished onto the development of novel microbicides against these viruses [1].

HSV establishes a lifelong infection in the host by infecting neurons and persisting latently inside these cells [42, 43]. Because sensorial nervous termini innervate the skin and mucosae, infections at these sites with HSVs can lead to neuron infection with a significantly high frequency $[44,45]$. Indeed, HSVs can readily gain access to neurons somewhat early after infecting epithelial cells, because these cells interact closely. Nevertheless, to restrict virus access to neurons and other tissues, the host has evolved an arsenal of antimicrobial determinants that aim at blocking infection, progression of infection, and microbe replication. However, as masters of immune evasion, HSVs encode molecular determinants that promote their stealth and overcome host defenses by overriding several of the antiviral elements of the host.

\section{HSV Infectious Cycle}

Herpes simplex viruses are enveloped viruses with numerous proteins and glycoproteins embedded on their exterior; whether 11 of the viral glycoproteins encoded by the viral genome are present on the virion surface remains to be thoroughly defined [46, 47]. Nevertheless, at least five viral glycoproteins have been implicated in viral entry: glycoprotein $\mathrm{B}(\mathrm{gB}), \mathrm{gC}, \mathrm{gD}, \mathrm{gH}$, and $\mathrm{gL}[48,49]$. gB acts both as a viral attachment protein and fusion protein by binding to heparan sulfates (HS) on the surface of susceptible host cells [50] and also is known to bind to paired immunoglobulin-like type 2 receptor (PILR) alpha $[51,52]$. A similar function has been described for gC in virus attachment, although only for HSV1 [53]. After gB-mediated attachment, gD binds to either of its receptors: nectin-1 (PVRL1; poliovirus receptor-related 1) expressed on the surface of most host cells or alternatively HVEM (Herpesvirus Entry Mediator, TNFRSF14), mainly expressed on immune cells [54, 55]. Furthermore, 3-O-sulfate HS has also been suggested as a potential receptor for $\mathrm{gD}$, although its physiological relevance requires additional research [56]. Binding of gD to its receptors is thought to induce conformational changes leading to the functional activation of a complex formed by $\mathrm{gH} / \mathrm{gL}$ [57]. Activated $\mathrm{gH} / \mathrm{gL}$ complex would in turn then promote changes in $\mathrm{gB}$ that activate the fusogenic properties of this protein and mediate the fusion of viral and host cell membranes [58, 59]. As an alternative pathway, HSVs can enter cells through endocytic vesicles $[60,61]$. In both cases, fusion of membranes promotes the entry of the capsid and accompanying viral proteins (tegument) into the cytoplasm [62]. The tegument is a complex mesh of $>20$ proteins beneath the envelope that wraps the viral capsid and contains molecular determinants that mediate, among others, the inhibition of cellular translation and apoptosis $[62,63]$. Once released into the cytoplasm, the capsid associates with microtubules through two tegument proteins VP1-2 (encoded by UL36) and UL37 and then travels to the outer nuclear membrane to bind to the host nuclear pore complex (NPC) to release the viral DNA into the nucleus $[62,63]$. Nucleoporin Nup358 has been associated with this process by docking VP1-2 onto the nuclear pore complex and facilitating the release of viral DNA into the nucleus through this macromolecular complex [64]. Once released into the nucleus, the viral DNA is transcribed by means of the host RNA-polymerase II activity $[65,66]$. However, not all HSV genes are expressed synchronously but instead in four consecutive rounds of transcription. First, immediate early genes (alpha) are transcribed, many of which encode for proteins contributing to immune evasion and work as factors controlling cell translation [67]. Then, follows the transcription of early genes (beta) that are required for DNA replication [68]. Finally, early late and late genes (gamma1 and gamma-2) are transcribed, which mainly encode for structural components of virions, such as capsid, tegument, and surface proteins $[69,70]$. These proteins can work as well as important immune evasion determinants (see below). To generate new virions, capsid proteins migrate from the cytoplasm into the nucleus to assemble with viral DNA and acquire at this location a layer of tegument proteins. Unlike other viruses, HSVs do not alter nuclear pores on exit but rather undergo envelopment in the inner nuclear membrane to form an enveloped capsid [71]. The capsid then travels through the perinuclear space and immediately fuses with the outer nuclear membrane thanks to glycoproteins $\mathrm{gB}$ and $\mathrm{gH}$, exposing a tegument-recovered capsid into the cytoplasm [72]. Once in the cytoplasm, the capsid is further coated with additional tegument proteins and is once again enveloped in the trans-Golgi network [73]. From here, virions are exported in vesicles to the cell surface and secreted. Although host tetherin (Bst-2 or CD317) has been shown to block the release of certain enveloped viruses from the cell surface, the HSV protein vhs (virion host shutoff protein, UL41) can counteract the antiviral function of this protein by depleting it [74]. Noteworthy, HSVs can also propagate directly onto adjacent 


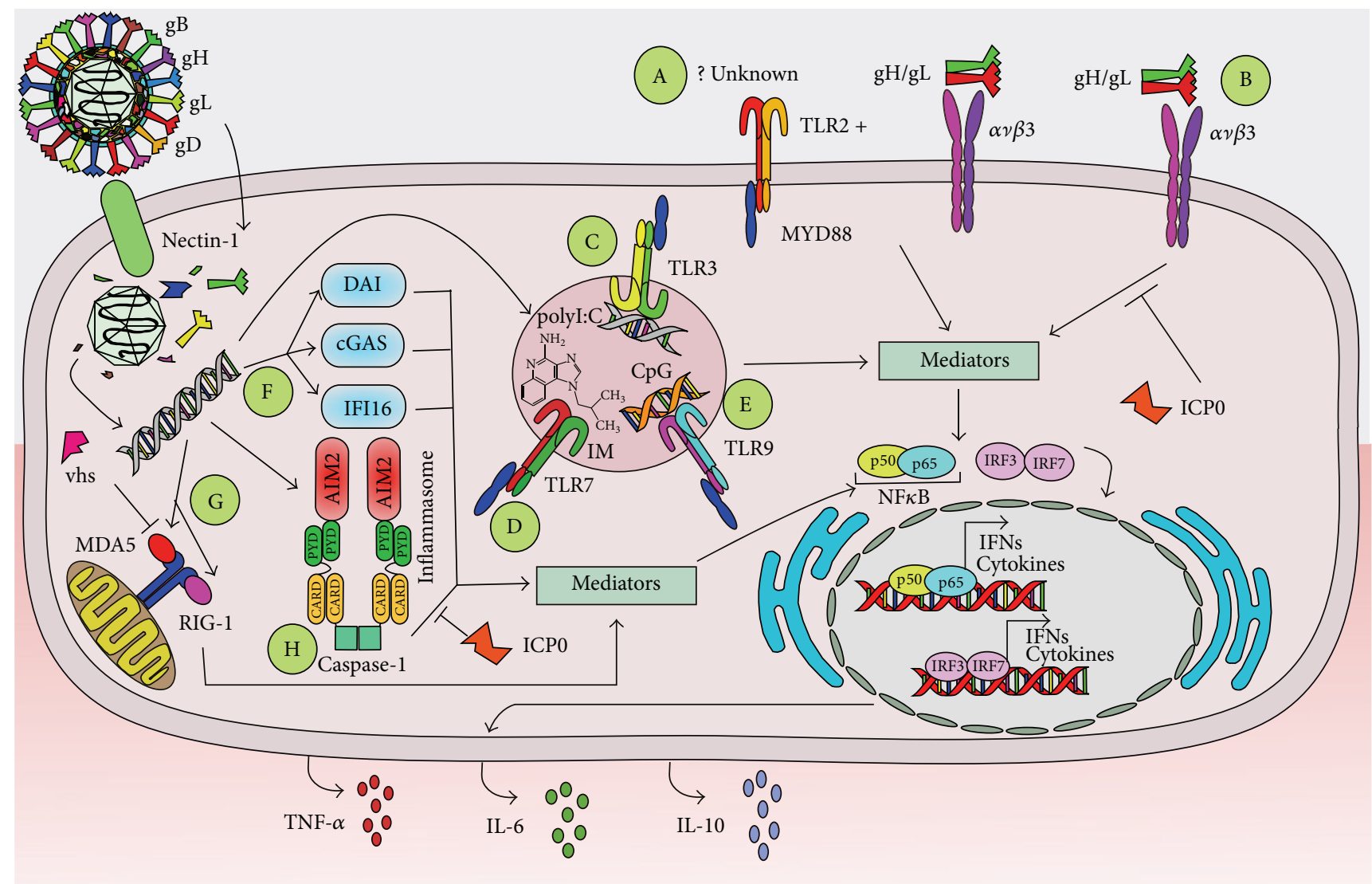

FIGURE 1: HSV s interfere with host detection of viral determinants. Immune and nonimmune cells express an array of pathogen recognition receptors intended to detect microbes, which ultimately lead to NF- $\kappa \mathrm{B}$ and IRF translocation into the nucleus and secretion of antiviral molecules, such as interferons and cytokines. A: Host cells can sense HSV determinants through TLR2, although the specific viral elements detected by this receptor are currently unknown. Intracellular signaling through TLR2 can occur with the help of integrin $\alpha \nu \beta 3$-binding after this receptor binds with the HSV complex gH/gL. B: Alternatively, integrin $\alpha \nu \beta 3$ can signal intracellularly on its own after gH/gL binding. This process can be interfered by ICP0 C: TLR3, D: TLR7, and E: TLR9 engagement by activating ligands, such as polyI:C, imiquimod (IM), and CpG-ODN, respectively, have been shown to play favorable roles against HSV infection by inducing activating pathways within cells that lead to the secretion of antiviral molecules. F: Nucleic acids generated during HSV infection can also be detected by host intracellular sensors, such as DAI, cGAS, and IFI16. G: The RIG-1/MDA5 complex can also detect virus-derived nucleic acids; however its function is blocked by viral vhs. H: Finally, the inflammasome is activated by HSV determinants, although HSV ICP0 can counteract its activity and negatively modulate its function.

cells through cell-cell interactions. In these circumstances, virus components are directed to the interface of cell-cell regions. This type of infection is used by HSVs to infect $\mathrm{T}$ cells, which has been shown to occur through infected fibroblasts in vitro $[75,76]$. This type of infection is mediated through a process called virological synapse and provides the virus a safe haven from neutralization by antibodies or complement (see below) $[77,78]$.

\section{Evasion of HSV Sensing by Host Receptors}

Immune and nonimmune host cells express an array of surface and intracellular receptors intended to sense microbial elements and initiating local and systemic antimicrobial responses. Such receptors, termed pathogen recognition receptors (PRRs), recognize Pathogen Associated Molecular Patterns (PAMPs), which consist among others of microbederived molecules, such as lipids, proteins and nucleic acids
[79]. An important family of PRRs is Toll-like receptors (TLRs), which upon binding with microbe elements lead to intracellular signaling cascades that promote early antiviral cellular responses and the secretion of soluble mediators that activate infected and noninfected neighboring cells, as well as the immune system [80-84].

It has been shown that HSVs induce the activation of TLR2 in primary vaginal epithelial cells and also immune cells, such as dendritic cells (DCs). Interestingly, it has been suggested that in keratinocytes, neural cells, and epithelial cells TLR2-mediated effects after virus infection require the cooperation of $\alpha \nu \beta 3$-integrin, likely due to the binding of the $\mathrm{HSV} \mathrm{gH} / \mathrm{gL}$ complex to this integrin, leading to NF- $\kappa \mathrm{B}$ activation, interferon production, and IL-10 secretion (Figure 1) $[85,86]$. In DCs, the activation of TLR2 induces a cell response that leads to the downstream activation of NF$\kappa \mathrm{B}$ and the transcription of immunomodulatory cytokines, such as IL-6, IL-8, IL-10, IL-12, and TNF- $\alpha$ [87]. Another 
study with DCs also showed that HSV recognition by TLR2 promoted IL- 6 and IL-12 secretion and proposed that this cytokine outcome was mediated, at least in part, by TLR9 modulation, suggesting a previously uncharacterized mechanism for sequential recognition of viruses via TLR2 through TLR9 [88]. Consistent with this notion, TLR2 $2^{-/-}$ knockout mice secrete low levels of MCP-1, a chemokine generally induced after TLR9 engagement [89]. Importantly, TLR2 ${ }^{-/-}$knockout mice display prolonged survival after HSV infection, as compared to wild-type and TLR4 ${ }^{-/-}$knockout mice. Despite reduced mortality, viral loads remained similar in TLR2-knockout and wild-type animals [90]. On the other hand, microglia from TLR2 ${ }^{-/-}$mice display delayed and attenuated production of reactive oxygen species (ROS) following viral infection and suffer lesser neuronal oxidative damage in mixed neural cell cultures, as compared to HSVinfected cells from wild-type animals [91].

TLR3 has also been described to play a role in HSV infection, especially for neurons and during viral brain infection. For instance, it has been shown that TLR3 deficiencies $\left(\mathrm{TLR}^{-/-}{ }^{-}\right.$) render astrocytes permissive to HSV infection, facilitating the establishment of CNS infection in animals. Consistently, it was shown that TLR3 expressed in astrocytes provided early control of HSV infection after viral entry into the central nervous system and induced type-I IFN responses in these cells. Remarkably, this TLR3 deficiency did not seem to affect innate immune responses [92]. Other studies have shown that astrocyte infection with HSV leads to TLR3 engagement and NF- $\kappa \mathrm{B}$ activation, upregulating the expression of TNF- $\alpha$ and IL- 6 with antiviral functions attributed to these two molecules (Figure 1) [93]. On the other hand, studies performed in humans carrying mutations that negatively modulate TLR3-mediated immunity have shown that these individuals are more prone to HSV encephalitis [94-96]. Consistent with these findings, a study with ex vivo differentiated neurons, astrocytes and oligodendrocytes derived from pluripotent stem cells from individuals with TLR3 deficiencies were shown to be more susceptible to HSV infection in vitro than control cells and displayed compromised interferon secretion. Interestingly, these effects depended significantly on the cell types analyzed [97]. On the other hand, mice pretreated either intravaginally or intraperitoneally with agonists for TLR3, such as polyI:C, suffer significantly less virus burden upon intravaginal viral challenge than nontreated animals, suggesting that activating this pathway would play favorable roles against HSV infection (Figure 1) [98].

As with TLR3, pretreating animals with TLR7 agonists, such as imiquimod, has also been shown to significantly reduce HSV burden in the genital tract after viral infection (Figure 1) [99]. Because of these results, imiquimod has been tested in humans, particularly against HSV strains that are resistant to acyclovir in immunocompromised patients, with favorable results [100-102]. However, it is important to note that another study found that imiquimod produced IFNindependent anti-HSV effects in nonimmune cells, which was independent of TLR signaling and IFN production, suggesting that TLR7 is likely not the only activation pathway involved in the favorable results observed against HSV in other studies [101].

TLR9 has also been shown to play roles in HSV infection, although similar to TLR3 and TLR7, because TLR9 agonists can positively influence the antiviral response against this pathogen. Indeed, mice pretreated intranasally with TLR9 agonists, such as CpG-oligodeoxynucleotides (CpG-ODNs), show reduced secretion of inflammatory cytokines, such as CCL2, IL-6, and CCL5, and reduced viral loads in the brain, resulting in mild encephalitis and increased survival rates, as compared to nontreated mice (Figure 1) [103]. Additionally, treatment with CpG-ODN containing unmethylated CpG provides protection against lethal vaginal challenge with HSV that was probably mediated by an intricate crosstalk between plasmacytoid DCs (pDCs) and vaginal stromal cells, as well as type-I IFNs [104-106]. Similar to the findings described with TLR3 and TLR7, these results suggest that modulating TLR9 signaling could be a promising strategy for limiting HSV infection in the host, although results from another group suggest that the antiviral effects mediated by TLR9 antagonists might not necessarily be mediated uniquely by intracellular events linked to TLR9 signaling [107]. Nevertheless, the results obtained with TLR9 agonists suggest that activating this TLR might be a useful strategy for controlling pathological responses induced by HSVs [108]. When combined with antivirals, such as acyclovir or antiinflammatory molecules, this strategy could improve current therapies against these viruses $[103,109]$.

Importantly, HSVs also induce the activation of non-TLR sensors in target cells. Namely, primary vaginal epithelial cells display increased activation of DNA sensors, such as DAI (DNA-dependent activator of interferon) and IFI16 (interferon-inducible 16), which trigger the secretion of IL6 (Figure 1) [110]. Another non-TLR host sensor includes $\alpha v \beta 3$-integrin, mentioned above with TLR2, which was also recently described to function as a major sensor of HSVs per se and activator of innate immunity by relocating the viruses' nectin-1 receptor to cholesterol-rich microdomains, thus, enabling virus uptake into dynamin 2-dependent acidic endosomes [111]. $\alpha v \beta 3$-integrin interacts with HSVs gH/gL complexes and is thought to signal at least through two pathways, one mediated by TLR2 with the activation of NF$\kappa \mathrm{B}$ and consequently induction of type-I interferons and another involving sarcoma- (SRC-) spleen tyrosine kinase(SYK-) caspase recruitment domain-containing protein 9(CARD9-) TRIF (TIR-domain-containing adapter-inducing interferon- $\beta$ ), which affects interferon regulatory factor 3 (IRF3) and IRF7 (Figure 1) [85, 86]. Importantly, the HSV viral protein ICP0 can counteract these $\alpha v \beta 3$-integrin signaling pathways to impair sensing of HSVs by infected cells [86]. A recent study suggests that TLR signaling via MyD88 and TRIF is expendable for controlling HSV infection and spread. Indeed, MyD88 ${ }^{-/-}, \mathrm{TRIF}^{-/-}$, and MyD88 ${ }^{-{ }^{-}}$$\mathrm{TRIF}^{-1-}$ double knockout mice displayed similar levels of HSV replication, when compared to wild-type mice, although this particular study was focused on HSV corneal infection. Importantly, the DNA sensor IFI-16/p204 was identified here to be key for the activation of IRF3 and IFN- $\alpha$ production 
for viral containment [112]. Consistently, silencing the genes that encode for IFI16/p204 inhibits the activation of IRF3 and NF- $\kappa$ B in response to HSV DNA [113]. Furthermore, a recent study showed that IFI16 depletion was associated with increased HSV yield, while its overexpression reduced the amount of virus obtained in cell cultures. ChIP assays found that IFI16 binds to HSV promoters and that cells devoid of this protein display increased amounts of host proteins that promote viral gene transcription at these locations. These findings suggest that IFI16 possesses antiviral functions and negatively modulates HSV transcription after binding to viral DNA [114]. Another intracellular, non-TLR receptor involved in the detection of HSV determinants is cyclic guanosine monophosphate-adenosine monophosphate (cGAMP) synthase (cGAS), a novel cytosolic DNA sensor (Figure 1). This protein has been shown to detect HSV DNA leading to typeI IFN (IFN-I) production in fibroblasts, macrophages, and dendritic cells and mice deficient for cGas succumb to death after infection with this virus [115]. Intracellular nucleic acid sensors RIG-I and MDA5 (retinoic acid-inducible gene 1 and melanoma differentiation-associated protein 5) also play antiviral roles in infected cells, yet vhs can selectively inhibit the expression of these molecules and prevent downstream IRF3 dimerization, as well as the translocation of this complex into the nucleus (Figure 1). By doing so, vhs can block signaling mediated through non-TLR pathways [116].

Another mechanism by which host cells can sense and initiate antiviral responses is through the activation of the inflammasome. The inflammasome is a multiprotein complex involved in translating pathogen recognition events into the secretion of inflammatory molecules, such as IL-1 $\beta$. Relevant inflammasome sensors include NLRP3 and AIM2 in the cytoplasm of cells and the nuclear sensor IFI16, discussed above. Recent studies have shown that HSV can induce early activation of the inflammasome and then, later on, inhibit its function during active infection [117]. Indeed, fibroblasts infected with HSV display activated IFI16 and NLRP3 and secrete IL-1 $\beta$ early after infection, although later on IFI16 is targeted to the proteasome by ICP0, likely releasing the break that IFI16 imposes on the transcription of HSV genes $[114,117]$. Subsequently, NLRP3 and AIM2 remain unaltered in cells with an inhibited inflammasome and little secretion of mature IL-1 $\beta$ [117].

\section{Modulation of Cell Viability and Early Antiviral Response}

Sensing of microbial components by immune and nonimmune cells can lead to cell apoptosis, as a host strategy to block virus replication and spread within cells. Importantly, HSV s encode viral determinants that block or delay the onset of apoptosis in infected cells, likely as a mechanism to extend the viability of its substrate for replication. This process has been proposed to be mediated by viral glycoproteins such as gJ and gD, as virus mutants lacking each one of these proteins initiated apoptotic cascades in epithelial cells (Figure 2(a)) [118]. Furthermore, the viral proteins ICP10PK and UL14 have also been shown to prevent apoptotic processes triggered in neurons and epithelial cells after viral infection (Figure 2(a)) [119-121]. Finally, US3 an HSV protein kinase conserved throughout alphaherpesviruses has also been shown to play a key role in blocking apoptosis induced by viral gene products and exogenous agents in epithelial cells. The antiapoptotic effects of US3 would be mediated through its interaction with programmed cell death protein 4 (PDCD4), which is retained in the nucleus of infected cells (Figure 2(a)) [122].

Nevertheless, other HSV proteins have been proposed to induce apoptosis and necrosis in host cells. For instance, HSV has been shown to induce necrosis in mouse fibroblast cells (L929 cells) mediated by the interaction between the viral ribonucleotide reductase large subunit ICP6 and RIP3 (receptor-interacting kinase 3) through RHIM domains, which activate MLKL (mixed lineage kinase domain-like protein). Consistently, an HSV ICP6 deletion mutant failed to cause effective necrosis of HSV-infected cells and mice lacking RIP3 exhibited severely impaired control of HSV replication and pathogenesis, highlighting the importance of the latter in limiting virus pathology [123]. Noteworthily, another study showed that early after HSV infection, natural killer cells (NK cells) suffer apoptosis through Fas/FasL when these cells interact with HSV-infected macrophages (Figure 2(b)) [124].

Similarly, HSV infection of dendritic cells induces apoptosis early after virus entry, particularly after the release of immunomodulatory cytokines $[125,126]$, and the viral protein $\gamma 34.5$ can interfere with DC autophagosome maturation, which is thought to play antiviral functions in these cells by degrading virus determinants (Figure 2(b)) [127, 128]. A similar role for autophagy has been proposed in the context of HSV infection in neurons as an alternative to IFN responses, which would likely result in the death of these cells or detrimental outcomes for the host. Indeed, neurons from dorsal root ganglia require autophagy to limit HSV replication in vivo and in vitro [128].

Antiviral functions in host cells are also mediated by Protein Kinase R (PKR), which phosphorylates the translation initiation factor EIF2A as a mechanism to inhibit the translation of RNA messengers upon viral infections. Importantly, this host protein has been shown to play a key role in controlling HSV replication in vitro and in vivo [129, 130]. However, HSVs have evolved molecular determinants that negatively modulate PKR function. For instance, viral $\gamma 34.5$ and US11 have been proposed to inhibit the activity of PKR to promote the translation of viral proteins (Figure 3 ) $[131,132]$. Furthermore, HSV s have evolved determinants that preferentially block the translation of host molecules over viral genes, in such a way to impair their antiviral activity. Indeed, HSVs vhs protein can mediate the degradation of host messenger RNA through their ribonuclease activity (Figure 3) [133]. The spatial-temporal delivery of vhs has evolved in such a way to display optimal activity early after infection for hampering host mRNA transcription and not to alter viral mRNAs transcribed later on [134].

Early sensing of viral determinants by host PRRs will generally lead to the activation of interferon pathways that aim at impairing virus replication and its shedding within the host [135]. Although cells in the genital tract infected with HSV-2 


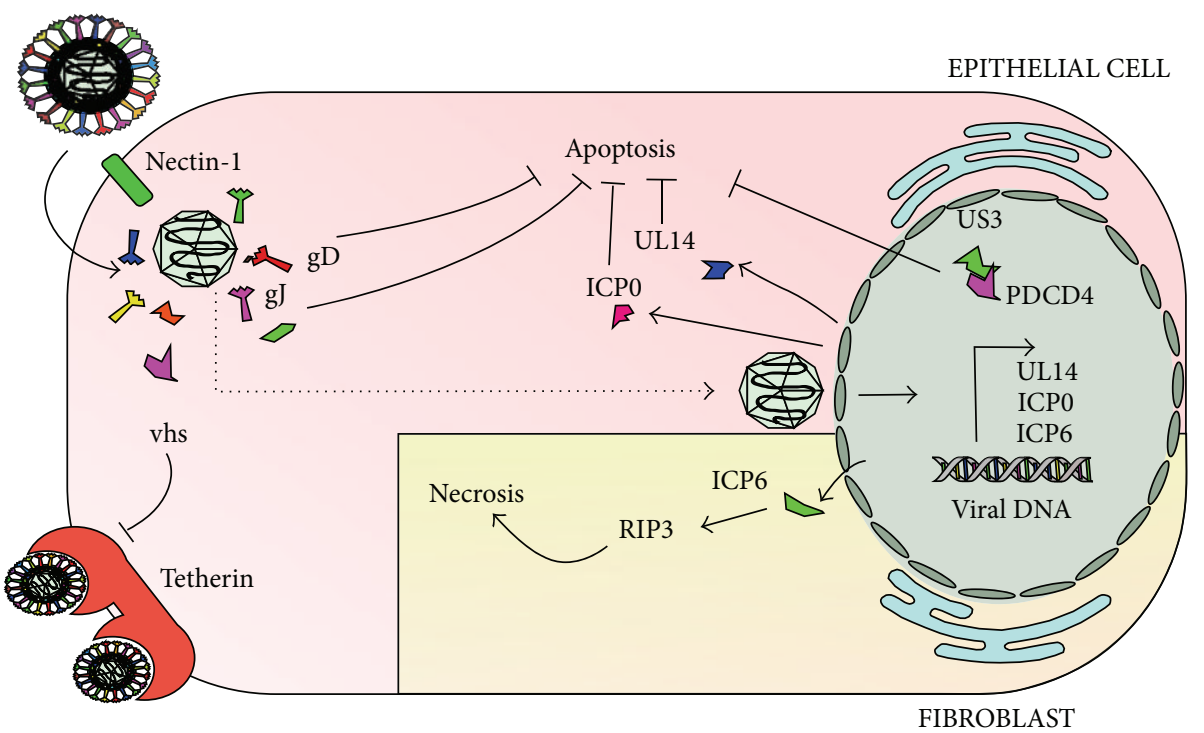

(a)

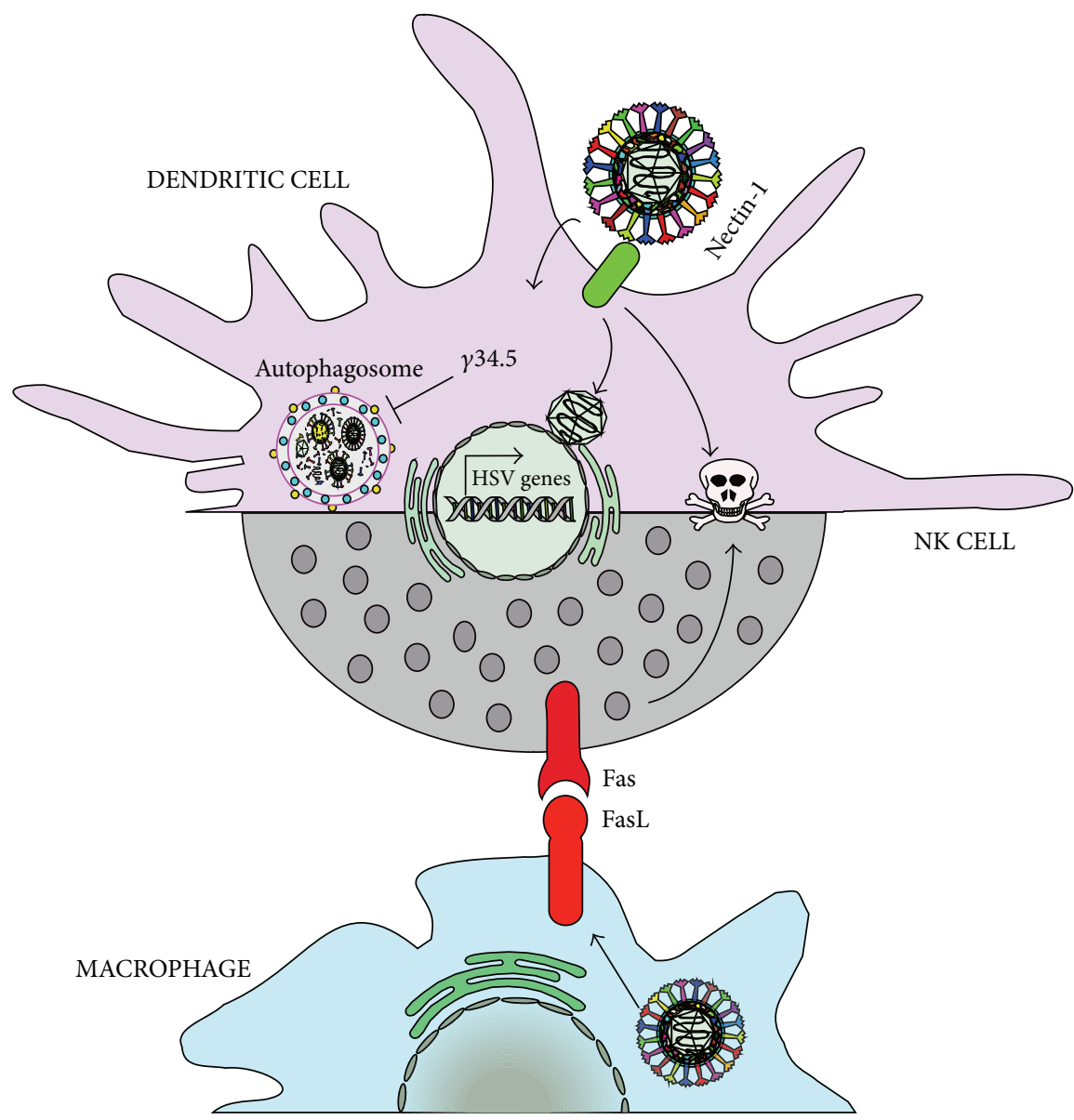

(b)

FIGURE 2: HSV interfere with cell viability. HSVs encode determinants that modulate cell viability. (a) Within epithelial cells, HSV can extend the survival of cells by blocking apoptosis thanks to viral proteins, such as gD, gJ, UL14, ICP0, and US3. Tetherin, a host antiviral factor involved in blocking virus release from the surface of infected cells, is blocked by HSV vhs. Contrarily, fibroblasts display necrosis upon infection with HSV, which would be mediated by ICP6. (b) Dendritic cells display apoptosis early after infection with HSVs by unknown viral determinants. The autophagosome, which mediates virus control in these and other cells, such as neurons, is inhibited by the viral protein $\gamma 34.5$. HSV also induces apoptosis of NK cells, albeit through Fas/FasL interactions between these cells and HSV-infected macrophages. 


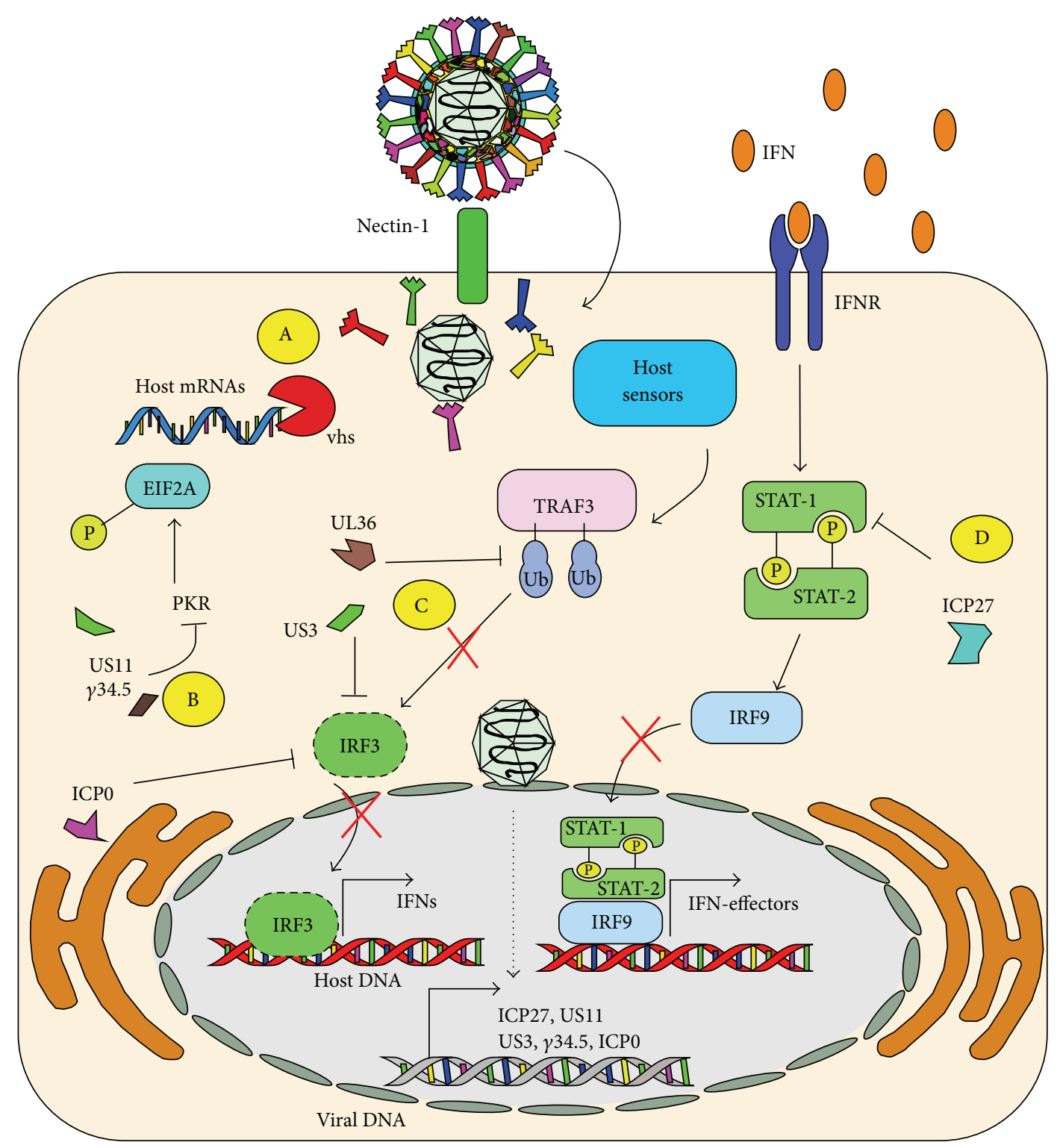

FIGURE 3: HSVs interfere with the induction of type-I interferons and interferon signaling. A: HSV vhs proteins interfere with cell protein translation by specifically degrading host mRNAs. B: Viral US11 and $\gamma 34.5$ interfere with host PKR function, by impairing its capacity to phosphorylate EIF2A, which blocks translation within infected cells. C: Host sensors activate TRAF3 after detecting HSV determinants, which normally leads to IRF3 activation. However, UL36 interferes with TRAF3 ubiquitination blocking its IRF3-activating capacity. ICP0 and US3 also interfere with IRF3 activation. Impaired IRF3 function will result in poor secretion of interferons by infected cells. D: Viral ICP27 interferes with STAT-1 signaling mediated by IFNR, which would otherwise lead to the secretion of antiviral effectors.

produce interferons in response to this virus, the magnitude of this response is generally hampered in the infected tissue, suggesting that these molecules likely play favorable antiviral roles [136]. Indeed, biopsies obtained from individuals infected with HSV show extremely low levels of type-I IFNs (IFN- $\alpha$ and IFN- $\beta$ ), despite the presence of a large number of cells capable of synthesizing these mediators, which suggests alterations in the host interferon response during HSV infection [137]. Consistent with this notion, type-I IFN receptor (IFNAR) knockout mice inoculated in the footpads with HSV manifest systemic viral infections that affect the lungs, liver, and spleens, although disease is nonlethal
[138]. Interference with host interferon pathways would be mediated, at least in part by the early viral protein ICP0, which can impair IRF3 function and block the transcription of genes regulated by this transcription factor [137]. Additionally, HSV ICP27 also inhibits type-I IFN signaling and interferes with nuclear accumulation of STAT-1 (Figure 3) [139]. Furthermore, the HSV Ser/Thr kinase US3 can hamper IFN- $\beta$ production by hyperphosphorylating IRF3 and by blocking the dimerization and nuclear translocation of this factor (Figure 3) [140]. Similarly, the tegument protein VP16 can also abrogate IFN- $\beta$ expression by inhibiting NF- $\kappa \mathrm{B}$ and IRF3 activation by impairing the recruitment of the 
coactivator CBP, without interfering with IRF3 dimerization, nuclear translocation, or its DNA binding activity (Figure 3) [141]. Yet, another mechanism by which HSV inhibits IFN- $\beta$ expression is through the deubiquitination of TRAF3 by the viral ubiquitin-specific protease UL36, which inhibits stimuli-induced IRF3 dimerization, promoter activation, and the transcription of IFN- $\beta$ (Figure 3) [142]. As noted, HSVs have evolved redundant and nonredundant mechanisms to specifically impair the function of host molecules that are key for the expression of antiviral molecules, namely, interferons.

The importance of IFNs in controlling infection by HSVs is highlighted by the fact that the frequency of genital herpetic recurrences can be reduced in patients by applying topical IFN- $\alpha$, which also reduces viral dissemination [143]. Moreover, the recently described interferon IFN- $\varepsilon$, characterized as a type-I IFN constitutively expressed by epithelial cells in the female and male reproductive tract, is proposed to be a potent antiviral host mediator that likely contributes to control of HSV infection [144, 145]. However, the exact mechanism by which IFN- $\varepsilon$ exerts its anti-HSV effects remains to be determined. Importantly, expression of IFN- $\varepsilon$ varies with the female hormonal cycle and seems to be limited to cells belonging to reproductive organs $[145,146]$.

\section{Secretion of Immunomodulatory Mediators Early after HSV Infection}

After HSV has blocked immediate host antiviral responses, which rely on the sensing of microbe elements and early interferon responses, cell damage resulting from virus replication likely spreads virus-elicited danger signals and damageassociated molecular patterns (DAMPs) onto other noninfected cells [117]. These neighboring cells, as well as patrolling immune cells, may sense these danger elements and initiate cytokine and chemokine responses that will modulate the milieu and other immune components [126, 147, 148]. Whether the soluble mediators produced in response to these danger signals or HSV itself promote the clearance of the virus or favor its persistence and spread in the host is largely unclear.

Because cytokine secretion is generally dependent on the canonical activation of NF- $\kappa \mathrm{B}$, HSVs have evolved several molecular mechanisms to modulate the activity of this transcription factor. A recent report showed that the viral DNA polymerase processivity factor UL42 interacts with p65/RelA and p50/NF- $\kappa$ B1 to block the translocation of NF- $\kappa \mathrm{B}$ to the nucleus in response to stimuli, such as TNF- $\alpha$ [149]. Consistently, another study found that HSV ICP0 inhibits TNF- $\alpha$-induced NF- $\kappa$ B activation, interacting similarly with p65/RelA and p50/NF- $\kappa$ B1 [150]. US3 has also been shown to significantly inhibit NF- $\kappa$ B activation and decrease the expression of inflammatory chemokines, such as IL-8 [151]. Furthermore, HSV VP16 also inhibits NF- $\kappa$ B activation and blocks IFN- $\beta$ production [141]. However, other HSV proteins, such as tegument protein UL37, have been shown to promote NF- $\kappa \mathrm{B}$ activation and IL- 8 secretion in keratinocytes [152]. Activation of NF- $\kappa \mathrm{B}$ after cell infection has also been reported to facilitate viral replication $[153,154]$.
Taken together, HSVs have evolved strategies to both block and promote the activation of NF- $\kappa \mathrm{B}$ within infected cells. Whether these opposing effects depend on the cell types targeted by these viruses or different stages of the infectious cycle requires further study. Nevertheless, these findings highlight the importance of NF- $\kappa \mathrm{B}$ modulation by HSVs after infection.

Despite interference with $\mathrm{NF}-\kappa \mathrm{B}$ activity, cells infected with HSV nonetheless secrete numerous modulatory cytokines and chemokines after infection or at the site of inflammation. For instance, HSV has been shown to induce the secretion of CCL2, IL- 8 , IL-6, and TNF- $\alpha$ in primary endometrial genital epithelial cells [155]. In vivo, HSV promotes CXCL9 expression in the cervical mucus of HSV-positive women [156]. Importantly, this chemokine and CXCL10 have been shown to play important roles against HSV in CNS infection in the mouse model, likely by recruiting $\mathrm{NK}$ and cytotoxic $\mathrm{T}$ cells to the infected tissue [157]. Similarly, a recent study proposed that CXCL10 is needed for establishing protective immunity against HSV-2 genital infection after vaccination with an attenuated HSV strain [158]. CCL2 induced upon HSV infection has been attributed a favorable role in corneal infection in the mouse model. Indeed, CCL $2^{-/-}$mice were unable to contain the virus and failed to recruit inflammatory monocytes to the infection site [159]. Furthermore, CCL2 expression driven by IFI16 recognition of HSV has been described to facilitate the recruitment of inflammatory monocytes to the infection site, as silencing of p204/IFI-16 resulted in the loss of CCL2 production and significantly more HSV shedding [159]. As indicated above, another cytokine induced after HSV infection is IL-6. Noteworthily, a protective role has been attributed to this cytokine in microglia, likely through downstream signaling of Signal Transducer and Activator of Transcription 3 (STAT3), although the precise mechanism leading to its protective role is unclear $[160,161]$. Mast cells have also been shown to secrete IL-6 early after HSV infection, as well as TNF- $\alpha$, yet these cytokines were not induced directly by HSV in this study but depended on supernatants from HSV-infected keratinocytes and the IL-33 receptor on the former cells. Importantly, mice lacking TNF- $\alpha$ or IL- 6 succumbed to death, consistent with a protective role for these cytokines [162]. Contrarily, a recent study suggested that treating mice with anti-TNF$\alpha$ in combination with the antiviral valacyclovir could significantly improve the prognosis of encephalitis caused by HSV [109].

One aspect that has brought important attention onto cytokines and chemokines produced after HSV infection is that some of the molecules secreted in the genital tract can favor host infection by other sexually transmitted pathogens, such as the human immunodeficiency virus (HIV) [30]. Indeed, infection with HSV-2 increases 3-4 times host susceptibility of acquiring HIV and, furthermore, coinfection increases the shedding of both viruses [27-29, 163]. These findings have been corroborated in a murine infection model [31]. The increased susceptibility to acquire HIV after HSV2 infection has been suggested to result, within others, by an increased recruitment of target cells for HIV, such as dendritic 
cells and $\mathrm{T}$ cells to the site of infection $[164,165]$, increased expression of HIV-receptor molecules at the surface or specific cell populations [166, 167], and reduced expression of cell surface molecules that actually promote the capture and degradation of HIV [168]. Furthermore, immune cells such as dendritic cells infected with HSV have been shown to produce soluble mediators that promote the reactivation of HIV from cells latently infected with the latter virus [126]. Regretfully, the identities of the soluble molecules that account for the observed effect have not been identified so far.

Besides upregulating the expression of certain cytokines and chemokines, HSVs can also reduce the expression of certain antiviral molecules, such as the secreted leucocyte protease inhibitor (SLPI). Indeed, HSV-infected cells secrete less SLPI, which reduces the infectivity of HSV in vitro [169]. Furthermore, a decrease in the expression of SLPI would likely promote an increase in the secretion of proinflammatory cytokines, which are associated with exacerbated damage to the infected tissues [169]. Nevertheless, virus-mediated inhibition of other chemokines could favor the host, such as CXCL2 which is secreted by monocytes in response to HSV which is known to recruit neutrophils that elicit damaging inflammatory immune responses to host cells and tissues, namely, neurons [170].

Despite the fact that HSVs have been extensively studied, it is surprising to note how little we know about the contribution of cytokines and chemokines induced upon infection by this virus to infection and pathology. Cytokines and chemokines induced by HSV infection will likely play different roles for the host, either favorable or antagonizing, depending on the tissue infected, whether it is skin, genitalia, eyes, or the central nervous system. Furthermore, differences in the nature and amounts of the cytokines and chemokines secreted upon viral infection, as well as the roles of these molecules on virus clearance and disease, will likely depend on whether infection is mediated by HSV-1 or HSV2. High throughput techniques such as multiplex cytokine arrays and the availability of numerous knockout mice for these molecules should provide new insights and valuable information on the role of these soluble mediators in HSV infection in the near future.

\section{HSV Interferes with Innate Immune Functions}

Innate immunity has evolved soluble components and specialized cells to block microbe infection, replication, and shedding. One such element is the complement. The complement is composed of serum proteins that, once triggered by microbial determinants or antibody bound to ligands, interact with each other in a cascade of events that lead to the damaging of the surfaces of the pathogen or cells infected with the microbe. However, HSVs have evolved molecular determinants to interfere with the function of complement protein $\mathrm{C} 5$ and block its downstream activating properties; this process is mediated by glycoprotein C $[78,171]$. By doing so, the virus likely extends its lifespan in the serum and that of the cells it infects.
NK cells play important roles against several viral pathogens; however their role in HSV infection is frequently debated. Although some studies propose key roles for these cells, others have underestimated their importance at controlling HSV infection [172, 173]. HSV can directly activate NK cells through TLR2; whether this interaction promotes viral clearance or not in vivo is still unclear [174]. HSV can also decrease the expression of NK-activating ligands such as MICA (MHC class I polypeptide-related sequence A) on the surface of infected cells, thus interfering with the effector activity of these cells. This process would be mediated by a late HSV gene product, which would mask, internalize, or retain MICA intracellularly $[175,176]$.

Natural killer T (iNKT) cells are CD1d-restricted T cells that express invariant TCR chains, as well as NK surface markers, and are specialized in recognizing polar lipids presented on the surface of CD1d molecules [177]. Although variations can be observed in the amount of iNKT cells present after HSV infection, changes in the number of cells and expression of markers on their surface are somewhat discrete when compared to patients in the steady state, suggesting potential modulation of these cells by HSVs [178]. Furthermore, infection with HSV has been described to negatively modulate the activity of NKT cells by simply directing CD1d molecules from the cell surface of infected cells into intracellular compartments, thus blocking antigen presentation $[179,180]$.

\section{Concluding Remarks}

World prevalence for HSVs is a truthful testimony of the success of these viruses in establishing latent infection in the host. Successful infection with HSVs is likely the result of a wide array of viral determinants encoded by these viruses with the capacity to interfere with multiple host factors intended to control early infection by pathogenic microbes. Indeed, HSVs effectively block early cellular antiviral mechanisms by extending the survival of cells that serve as substrates, hence favoring virus production and killing cells that initiate and modulate effective antiviral immune responses, such as DCs. Additionally, these viruses promote their stealth by interfering with their sensing by infected cells and by mounting somewhat modest interferon and cytokine responses that favor their replication and shedding. These phenomena will ultimately allow these viruses to reach cells needed for establishing latency: neurons. Noteworthily, important progress has been made in the last years in identifying early antiviral components elicited and blocked by HSVs. These studies will hopefully lead to the identification and development of drugs that specifically interfere with viral processes. Noteworthily, findings, such as those related to the activation of particular TLRs that favor host responses against these viruses, will undoubtedly contribute to the development of novel antiviral therapies. Indeed, potentiating early antiviral functions in the host before exposure could be as effective as novel anti-HSV microbicides currently under development, while an effective vaccine against these viruses reaches the clinic. 


\section{Conflict of Interests}

The authors declare that there is no conflict of interests regarding the publication of this paper.

\section{Acknowledgments}

Authors are supported by Grants CRP-ICGEB CRP/CHI1401, COPEC-UC J-139, FONDECYT no. 1140011, FONDECYT no. 1140010, FONDECYT no. 11075060, FONDECYT no. 1100926, FONDECYT no. 1110518, and FONDECYT no. 1110397 and the Millennium Institute on Immunology and Immunotherapy (no. P09/016-F). Angello R. Retamal-Díaz is a CONICYT fellow. Alexis M. Kalergis is Chaire De La Région Pays De La Loire, Chercheur Etranger d'Excellence, and a CDD-DR INSERM.

\section{References}

[1] P. A. Suazo, E. I. Tognarelli, A. M. Kalergis, and P. A. González, "Herpes simplex virus 2 infection: molecular association with HIV and novel microbicides to prevent disease," Medical Microbiology and Immunology, vol. 204, no. 2, pp. 161-176, 2015.

[2] B. P. Yawn and D. Gilden, "The global epidemiology of herpes zoster," Neurology, vol. 81, no. 10, pp. 928-930, 2013.

[3] Centers for Disease Control and Prevention, "Seroprevalence of herpes simplex virus type 2 among persons aged 14-49 YearsUnited States, 2005-2008," Morbidity and Mortality Weekly Report, vol. 59, no. 15, pp. 456-459, 2010.

[4] K. J. Looker, G. P. Garnett, and G. P. Schmid, "An estimate of the global prevalence and incidence of herpes simplex virus type 2 infection," Bulletin of the World Health Organization, vol. 86, no. 10, pp. 805-812, 2008.

[5] N. Dickson, A. Righarts, T. van Roode, C. Paul, J. Taylor, and A. L. Cunningham, "HSV-2 incidence by sex over four age periods to age 38 in a birth cohort," Sexually Transmitted Infections, vol. 90, no. 3, pp. 243-245, 2014.

[6] B. Grinde, "Herpesviruses: latency and reactivation-viral strategies and host response," Journal of Oral Microbiology, vol. 5, Article ID 22766, 2013.

[7] A. W. Kolb, C. Ané, and C. R. Brandt, "Using HSV-1 genome phylogenetics to track past human migrations," PLOS ONE, vol. 8, no. 10, Article ID e76267, 2013.

[8] B. Roizman and R. J. Whitley, "The nine ages of herpes simplex virus," Herpes, vol. 8, no. 1, pp. 23-27, 2001.

[9] C. M. Roberts, J. R. Pfister, and S. J. Spear, "Increasing proportion of herpes simplex virus type 1 as a cause of genital herpes infection in college students," Sexually Transmitted Diseases, vol. 30, no. 10, pp. 797-800, 2003.

[10] S. Buxbaum, M. Geers, G. Gross, H. Schöfer, H. F. Rabenau, and H. W. Doerr, "Epidemiology of herpes simplex virus types 1 and 2 in Germany: what has changed?" Medical Microbiology and Immunology, vol. 192, no. 3, pp. 177-181, 2003.

[11] P. V. Coyle, H. J. O’Neill, D. E. Wyatt, C. McCaughey, S. Quah, and M. O. McBride, "Emergence of herpes simplex type 1 as the main cause of recurrent genital ulcerative disease in women in Northern Ireland," Journal of Clinical Virology, vol. 27, no. 1, pp. 22-29, 2003.

[12] V. S. S. Pereira, R. N. C. Moizeis, T. A. A. M. Fernandes, J. M. G. Araújo, R. V. Meissner, and J. V. Fernandes, "Herpes simplex virus type 1 is the main cause of genital herpes in women of Natal, Brazil," European Journal of Obstetrics Gynecology and Reproductive Biology, vol. 161, no. 2, pp. 190-193, 2012.

[13] F. Xu, M. R. Sternberg, B. J. Kottiri et al., "Trends in herpes simplex virus type 1 and type 2 seroprevalence in the United States," The Journal of the American Medical Association, vol. 296, no. 8, pp. 964-973, 2006.

[14] R. Horowitz, S. Aierstuck, E. A. Williams, and B. Melby, "Herpes simplex virus infection in a university health population: clinical manifestations, epidemiology, and implications," Journal of American College Health, vol. 59, no. 2, pp. 69-74, 2010.

[15] D. I. Bernstein, A. R. Bellamy, E. W. Hook et al., "Epidemiology, clinical presentation, and antibody response to primary infection with herpes simplex virus type 1 and type 2 in young women," Clinical Infectious Diseases, vol. 56, no. 3, pp. 344-351, 2013.

[16] Z. Samra, E. Scherf, and M. Dan, "Herpes simplex virus type 1 is the prevailing cause of genital herpes in the Tel Aviv area, Israel," Sexually Transmitted Diseases, vol. 30, no. 10, pp. 794-796, 2003.

[17] K. Manavi, A. McMillan, and M. Ogilvie, "Herpes simplex virus type 1 remains the principal cause of initial anogenital herpes in Edinburgh, Scotland," Sexually Transmitted Diseases, vol. 31, no. 5, pp. 322-324, 2004.

[18] O. Kortekangas-Savolainen, E. Orhanen, T. Puodinketo, and T. Vuorinen, "Epidemiology of genital herpes simplex virus type 1 and 2 infections in Southwestern Finland during a 10-year period (2003-2012)," Sexually Transmitted Diseases, vol. 41, no. 4, pp. 268-271, 2014.

[19] R. F. Nieuwenhuis, G. J. J. van Doornum, P. G. H. Mulder, H. A. M. Neumann, and W. I. van der Meijden, "Importance of herpes simplex virus type-1 (HSV-1) in primary genital herpes," Acta Dermato-Venereologica, vol. 86, no. 2, pp. 129-134, 2006.

[20] N. Ryder, F. Jin, A. M. McNulty, A. E. Grulich, and B. Donovan, "Increasing role of herpes simplex virus type 1 in first-episode anogenital herpes in heterosexual women and younger men who have sex with men, 1992-2006," Sexually Transmitted Infections, vol. 85, no. 6, pp. 416-419, 2009.

[21] A. V. Farooq and D. Shukla, "Herpes simplex epithelial and stromal keratitis: an epidemiologic update," Survey of Ophthalmology, vol. 57, no. 5, pp. 448-462, 2012.

[22] S. Kaye and A. Choudhary, "Herpes simplex keratitis," Progress in Retinal and Eye Research, vol. 25, no. 4, pp. 355-380, 2006.

[23] W. E. Lafferty, R. W. Coombs, J. Benedetti, C. Critchlow, and L. Corey, "Recurrences after oral and genital herpes simplex virus infection. Influence of site of infection and viral type," The New England Journal of Medicine, vol. 316, no. 23, pp. 1444-1449, 1987.

[24] L. Solomon, M. J. Cannon, M. Reyes, J. M. Graber, N. T. Wetherall, and W. C. Reeves, "Epidemiology of recurrent genital herpes simplex virus types 1 and 2," Sexually Transmitted Infections, vol. 79, no. 6, pp. 456-459, 2003.

[25] M. Janier, C. Scieux, R. Méouchi et al., "Virological, serological and epidemiological study of 255 consecutive cases of genital herpes in a sexually transmitted disease clinic of Paris (France): a prospective study," International Journal of STD and AIDS, vol. 17, no. 1, pp. 44-49, 2006.

[26] J. Benedetti, L. Corey, and R. Ashley, "Recurrence rates in genital herpes after symptomatic first-episode infection," Annals of Internal Medicine, vol. 121, no. 11, pp. 847-854, 1994.

[27] J. N. Wasserheit, "Epidemiological synergy: interrelationships between human immunodeficiency virus infection and other sexually transmitted diseases," Sexually Transmitted Diseases, vol. 19, no. 2, pp. 61-77, 1992. 
[28] E. E. Freeman, H. A. Weiss, J. R. Glynn, P. L. Cross, J. A. Whitworth, and R. J. Hayes, "Herpes simplex virus 2 infection increases HIV acquisition in men and women: systematic review and meta-analysis of longitudinal studies," AIDS, vol. 20, no. 1, pp. 73-83, 2006.

[29] R. V. Barnabas, J. N. Wasserheit, Y. Huang et al., "Impact of herpes simplex virus type 2 on HIV-1 acquisition and progression in an HIV vaccine trial (the step study)," Journal of Acquired Immune Deficiency Syndromes, vol. 57, no. 3, pp. 238244, 2011.

[30] L. Masson, K. Mlisana, F. Little et al., "Defining genital tract cytokine signatures of sexually transmitted infections and bacterial vaginosis in women at high risk of HIV infection: a cross-sectional study," Sexually Transmitted Infections, vol. 90, no. 8, pp. 580-587, 2014.

[31] B. Nixon, E. Fakioglu, M. Stefanidou et al., "Genital Herpes simplex virus Type 2 infection in humanized HIV-transgenic mice triggers HIV shedding and is associated with greater neurological disease," Journal of Infectious Diseases, vol. 209, no. 4, pp. 510-522, 2014.

[32] A. Mujugira, A. S. Magaret, J. M. Baeten, C. Celum, and J. Lingappa, "Risk factors for HSV-2 infection among sexual partners of HSV-2/HIV-1 Co-infected persons," BMC Research Notes, vol. 4, article 64, 2011.

[33] A. Mujugira, A. S. Magaret, C. Celum et al., "Daily acyclovir to decrease herpes simplex virus type 2 (HSV-2) transmission from HSV-2/HIV-1 coinfected persons: a randomized controlled trial," The Journal of Infectious Diseases, vol. 208, no. 9, pp. 1366-1374, 2013.

[34] T. Schacker, J. Zeh, H. Hu, M. Shaughnessy, and L. Corey, "Changes in plasma human immunodeficiency virus type 1 RNA associated with herpes simplex virus reactivation and suppression," Journal of Infectious Diseases, vol. 186, no. 12, pp. 1718-1725, 2002.

[35] X.-P. Zhu, Z. S. Muhammad, J.-G. Wang, W. Lin, S.-K. Guo, and W. Zhang, "HSV-2 vaccine: current status and insight into factors for developing an efficient vaccine," Viruses, vol. 6, no. 2, pp. 371-390, 2014.

[36] A. R. Retamal-Díaz, P. A. Suazo, I. Garrido et al., "Immune evasion by herpes simplex virus," Revista Chilena de Infectología, vol. 32, no. 1, pp. 58-71, 2015.

[37] W. P. Halford, "Antigenic breadth: a missing ingredient in HSV2 subunit vaccines?” Expert Review of Vaccines, vol. 13, no. 6, pp. 691-710, 2014.

[38] T. M. Cairns, Z.-Y. Huang, J. C. Whitbeck et al., "Dissection of the antibody response against herpes simplex virus glycoproteins in naturally infected humans," Journal of Virology, vol. 88, no. 21, pp. 12612-12622, 2014.

[39] A. A. Chentoufi, E. Kritzer, D. M. Yu, A. B. Nesburn, and L. Benmohamed, "Towards a rational design of an asymptomatic clinical herpes vaccine: the old, the new, and the unknown," Clinical \& Developmental Immunology, vol. 2012, Article ID 187585, 16 pages, 2012.

[40] R. B. Belshe, T. C. Heineman, D. I. Bernstein et al., "Correlate of immune protection against HSV-1 genital disease in vaccinated women," The Journal of Infectious Diseases, vol. 209, no. 6, pp. 828-836, 2014.

[41] R. B. Belshe, P. A. Leone, D. I. Bernstein et al., "Efficacy results of a trial of a herpes simplex vaccine," The New England Journal of Medicine, vol. 366, no. 1, pp. 34-43, 2012.

[42] H.-W. Yao, P. Ling, Y.-Y. Tung, S.-M. Hsu, and S.-H. Chen, "In vivo reactivation of latent herpes simplex virus 1 in mice can occur in the brain before occurring in the trigeminal ganglion," Journal of Virology, vol. 88, no. 19, pp. 11264-11270, 2014.

[43] T. P. Margolis, Y. Imai, L. Yang, V. Vallas, and P. R. Krause, "Herpes Simplex Virus type 2 (HSV-2) establishes latent infection in a different population of ganglionic neurons than HSV-1: role of latency-associated transcripts," Journal of Virology, vol. 81, no. 4, pp. 1872-1878, 2007.

[44] M. I. Gonzalez and N. A. Sanjuan, "Striated muscle involvement in experimental oral infection by herpes simplex virus type 1 ," Journal of Oral Pathology \& Medicine, vol. 42, no. 6, pp. 486490, 2013.

[45] M. M. Linehan, S. Richman, C. Krummenacher, R. J. Eisenberg, G. H. Cohen, and A. Iwasaki, "In vivo role of nectin-1 in entry of herpes simplex virus type 1 (HSV-1) and HSV-2 through the vaginal mucosa," Journal of Virology, vol. 78, no. 5, pp. 25302536, 2004

[46] J. Rajcani and A. Vojvodova, "The role of herpes simplex virus glycoproteins in the virus replication cycle," Acta Virologica, vol. 42, no. 2, pp. 103-118, 1998.

[47] J. Akhtar and D. Shukla, "Viral entry mechanisms: cellular and viral mediators of herpes simplex virus entry," The FEBS Journal, vol. 276, no. 24, pp. 7228-7236, 2009.

[48] A. Turner, B. Bruun, T. Minson, and H. Browne, "Glycoproteins $\mathrm{gB}, \mathrm{gD}$, and $\mathrm{gHgL}$ of herpes simplex virus type 1 are necessary and sufficient to mediate membrane fusion in a Cos cell transfection system," Journal of Virology, vol. 72, no. 1, pp. 873875, 1998.

[49] E. Avitabile, C. Forghieri, and G. Campadelli-Fiume, "Cross talk among the glycoproteins involved in herpes simplex virus entry and fusion: the interaction between $\mathrm{gB}$ and $\mathrm{gH} / \mathrm{gL}$ does not necessarily require gD," Journal of Virology, vol. 83, no. 20, pp. 10752-10760, 2009.

[50] D. Atanasiu, T. M. Cairns, J. C. Whitbeck et al., "Regulation of herpes simplex virus gB-induced cell-cell fusion by mutant forms of $\mathrm{gH} / \mathrm{gL}$ in the absence of $\mathrm{gD}$ and cellular receptors," mBio, vol. 4, no. 2, Article ID e00046-13, 2013.

[51] T. Satoh, J. Arii, T. Suenaga et al., "PILR $\alpha$ is a herpes simplex virus-1 entry coreceptor that associates with glycoprotein B," Cell, vol. 132, no. 6, pp. 935-944, 2008.

[52] J. Arii, J. Wang, T. Morimoto et al., "A single-amino-acid substitution in herpes simplex virus 1 envelope glycoprotein $\mathrm{B}$ at a site required for binding to the paired immunoglobulinlike type 2 receptor $\alpha$ (PILR $\alpha$ ) abrogates PILR $\alpha$-dependent viral entry and reduces pathogenesis," Journal of Virology, vol. 84, no. 20, pp. 10773-10783, 2010.

[53] B. C. Herold, D. WuDunn, M. Soltys, and P. G. Spear, "Glycoprotein $\mathrm{C}$ of herpes simplex virus type 1 plays a principal role in the adsorption of virus to cells and in infectivity," Journal of Virology, vol. 65, no. 3, pp. 1090-1098, 1991.

[54] H. Matsushima, A. Utani, H. Endo et al., "The expression of nectin-1 $\alpha$ in normal human skin and various skin tumours," British Journal of Dermatology, vol. 148, no. 4, pp. 755-762, 2003.

[55] M. W. Steinberg, Y. Huang, Y. Wang-Zhu et al., "BTLA interaction with HVEM expressed on $\mathrm{CD}^{+} \mathrm{T}$ cells promotes survival and memory generation in response to a bacterial infection," PLoS ONE, vol. 8, no. 10, Article ID e77992, 2013.

[56] J. Liu, Z. Shriver, R. Marshall Pope et al., "Characterization of a heparan sulfate octasaccharide that binds to herpes simplex virus type 1 glycoprotein D," Journal of Biological Chemistry, vol. 277, no. 36, pp. 33456-33467, 2002.

[57] E. Lazear, J. C. Whitbeck, Y. Zuo et al., "Induction of conformational changes at the $\mathrm{N}$-terminus of herpes simplex virus 
glycoprotein D upon binding to HVEM and nectin-1,' Virology, vol. 448, pp. 185-195, 2014.

[58] D. Fusco, C. Forghieri, and G. Campadelli-Fiume, "The profusion domain of herpes simplex virus glycoprotein $\mathrm{D}(\mathrm{gD})$ interacts with the $\mathrm{gD} \mathrm{N}$ terminus and is displaced by soluble forms of viral receptors," Proceedings of the National Academy of Sciences of the United States of America, vol. 102, no. 26, pp. 9323-9328, 2005.

[59] C. Krummenacher, V. M. Supekar, J. C. Whitbeck et al., "Structure of unliganded HSV gD reveals a mechanism for receptor-mediated activation of virus entry," EMBO Journal, vol. 24, no. 23, pp. 4144-4153, 2005.

[60] A. V. Nicola, A. M. McEvoy, and S. E. Straus, "Roles for endocytosis and low $\mathrm{pH}$ in herpes simplex virus entry into $\mathrm{HeLa}$ and Chinese hamster ovary cells," Journal of Virology, vol. 77, no. 9, pp. 5324-5332, 2003.

[61] R. S. B. Milne, A. V. Nicola, J. C. Whitbeck, R. J. Eisenberg, and G. H. Cohen, "Glycoprotein D receptor-dependent, low$\mathrm{pH}$-independent endocytic entry of herpes simplex virus type 1," Journal of Virology, vol. 79, no. 11, pp. 6655-6663, 2005.

[62] K. Döhner, A. Wolfstein, U. Prank et al., "Function of dynein and dynactin in herpes simplex virus capsid transport," Molecular Biology of the Cell, vol. 13, no. 8, pp. 2795-2809, 2002.

[63] H. Granzow, B. G. Klupp, and T. C. Mettenleiter, "Entry of pseudorabies virus: an immunogold-labeling study," Journal of Virology, vol. 79, no. 5, pp. 3200-3205, 2005.

[64] A. M. Copeland, W. W. Newcomb, and J. C. Brown, "Herpes simplex virus replication: roles of viral proteins and nucleoporins in capsid-nucleus attachment," Journal of Virology, vol. 83, no. 4, pp. 1660-1668, 2009.

[65] L. E. Holland, K. P. Anderson, C. Shipman Jr., and E. K. Wagner, "Viral DNA synthesis is required for the efficient expression of specific herpes simplex virus type 1 mRNA species," Virology, vol. 101, no. 1, pp. 10-24, 1980.

[66] A. D. B. Kops and D. M. Knipe, "Formation of DNA replication structures in herpes virus-infected cells requires a viral DNA binding protein," Cell, vol. 55, no. 5, pp. 857-868, 1988.

[67] L. Silva, H. S. Oh, L. Chang, Z. Yan, S. J. Triezenberg, and D. M. Knipe, "Roles of the nuclear lamina in stable nuclear association and assembly of a herpesviral transactivator complex on viral immediate-early genes," mBio, vol. 3, no. 1, 2012.

[68] W. Wu, Z. Guo, X. Zhang et al., "A microRNA encoded by HSV1 inhibits a cellular transcriptional repressor of viral immediate early and early genes," Science China Life Sciences, vol. 56, no. 4, pp. 373-383, 2013.

[69] S. Chen, L. Mills, P. Perry et al., "Transactivation of the major capsid protein gene of herpes simplex virus type 1 requires a cellular transcription factor," Journal of Virology, vol. 66, no. 7, pp. 4304-4314, 1992.

[70] J. Rajčáni, V. Andrea, and R. Ingeborg, "Peculiarities of herpes simplex virus (HSV) transcription: an overview," Virus Genes, vol. 28, no. 3, pp. 293-310, 2004.

[71] H. Hofemeister and P. O'Hare, "Nuclear pore composition and gating in herpes simplex virus-infected cells," Journal of Virology, vol. 82, no. 17, pp. 8392-8399, 2008.

[72] A. Farnsworth, T. W. Wisner, M. Webb et al., "Herpes simplex virus glycoproteins $\mathrm{gB}$ and $\mathrm{gH}$ function in fusion between the virion envelope and the outer nuclear membrane," Proceedings of the National Academy of Sciences of the United States of America, vol. 104, no. 24, pp. 10187-10192, 2007.
[73] S. Turcotte, J. Letellier, and R. Lippé, "Herpes simplex virus type 1 capsids transit by the trans-Golgi network, where viral glycoproteins accumulate independently of capsid egress," Journal of Virology, vol. 79, no. 14, pp. 8847-8860, 2005.

[74] H. L. Zenner, R. Mauricio, G. Banting, and C. M. Crump, "Herpes simplex virus 1 counteracts tetherin restriction via its virion host shutoff activity," Journal of Virology, vol. 87, no. 24, pp. 13115-13123, 2013.

[75] D. C. Johnson, M. Webb, T. W. Wisner, and C. Brunetti, "Herpes simplex virus $\mathrm{gE} / \mathrm{gI}$ sorts nascent virions to epithelial cell junctions, promoting virus spread," Journal of Virology, vol. 75, no. 2, pp. 821-833, 2001.

[76] M. Aubert, M. Yoon, D. D. Sloan, P. G. Spear, and K. R. Jerome, "The virological synapse facilitates herpes simplex virus entry into T cells," Journal of Virology, vol. 83, no. 12, pp. 6171-6183, 2009.

[77] J. M. Lubinski, H. M. Lazear, S. Awasthi, F. Wang, and H. M. Friedman, "The herpes simplex virus 1 IgG Fc receptor blocks antibody-mediated complement activation and antibody-dependent cellular cytotoxicity in vivo," Journal of Virology, vol. 85, no. 7, pp. 3239-3249, 2011.

[78] L. M. Hook, J. M. Lubinski, M. Jiang, M. K. Pangburn, and H. M. Friedman, "Herpes simplex virus type 1 and 2 glycoprotein $\mathrm{C}$ prevents complement-mediated neutralization induced by natural immunoglobulin M antibody," Journal of Virology, vol. 80, no. 8, pp. 4038-4046, 2006.

[79] D. Tang, R. Kang, C. B. Coyne, H. J. Zeh, and M. T. Lotze, "PAMPs and DAMPs: signal 0s that spur autophagy and immunity," Immunological Reviews, vol. 249, no. 1, pp. 158-175, 2012.

[80] L. Alexopoulou, A. C. Holt, R. Medzhitov, and R. A. Flavell, "Recognition of double-stranded RNA and activation of NF- $\kappa$ B by Toll-like receptor 3," Nature, vol. 413, no. 6857, pp. 732-738, 2001.

[81] S. S. Diebold, T. Kaisho, H. Hemmi, S. Akira, and C. R. e Sousa, "Innate antiviral responses by means of TLR7-mediated recognition of single-stranded RNA," Science, vol. 303, no. 5663, pp. 1529-1531, 2004.

[82] H. Hemmi, T. Kaisho, O. Takeuchi et al., "Small-antiviral compounds activate immune cells via the TLR7 MyD88-dependent signaling pathway," Nature Immunology, vol. 3, no. 2, pp. 196200, 2002.

[83] J. Melchjorsen, "Sensing herpes: more than toll," Reviews in Medical Virology, vol. 22, no. 2, pp. 106-121, 2012.

[84] N. Martinez-Martin and A. Viejo-Borbolla, "Toll-like receptormediated recognition of herpes simplex virus," Frontiers in Bioscience, vol. 2, no. 2, pp. 718-729, 2010.

[85] T. Gianni, V. Leoni, and G. Campadelli-Fiume, "Type I interferon and NF- $\kappa \mathrm{B}$ activation elicited by herpes simplex virus $\mathrm{gH} / \mathrm{gL}$ via $\alpha \mathrm{v} \beta 3$ integrin in epithelial and neuronal cell lines," Journal of Virology, vol. 87, no. 24, pp. 13911-13916, 2013.

[86] T. Gianni, V. Leoni, L. S. Chesnokova, L. M. Hutt-Fletcher, and G. Campadelli-Fiume, "alphavbeta3-integrin is a major sensor and activator of innate immunity to herpes simplex virus-1," Proceedings of the National Academy of Sciences of the United States of America, vol. 109, no. 48, pp. 19792-19797, 2012.

[87] M. E. Ariza, R. Glaser, and M. V. Williams, "Human herpesviruses-encoded dUTPases: a family of proteins that modulate dendritic cell function and innate immunity," Frontiers in Microbiology, vol. 5, article 504, 2014.

[88] A. Sato, M. M. Linehan, and A. Iwasaki, "Dual recognition of herpes simplex viruses by TLR2 and TLR9 in dendritic cells," 
Proceedings of the National Academy of Sciences of the United States of America, vol. 103, no. 46, pp. 17343-17348, 2006.

[89] S. Takeda, D. Miyazaki, S.-I. Sasaki et al., "Roles played by Tolllike receptor-9 in corneal endothelial cells after herpes simplex virus type 1 infection," Investigative Ophthalmology and Visual Science, vol. 52, no. 9, pp. 6729-6736, 2011.

[90] E. A. Kurt-Jones, M. Chan, S. Zhou et al., "Herpes simplex virus 1 interaction with Toll-like receptor 2 contributes to lethal encephalitis," Proceedings of the National Academy of Sciences of the United States of America, vol. 101, no. 5, pp. 1315-1320, 2004.

[91] S. J. Schachtele, S. Hu, M. R. Little, and J. R. Lokensgard, "Herpes simplex virus induces neural oxidative damage via microglial cell Toll-like receptor-2," Journal of Neuroinflammation, vol. 7, article 35, 2010.

[92] L. S. Reinert, L. Harder, C. K. Holm et al., "TLR3 deficiency renders astrocytes permissive to herpes simplex virus infection and facilitates establishment of CNS infection in mice," Journal of Clinical Investigation, vol. 122, no. 4, pp. 1368-1376, 2012.

[93] Z. Liu, Y. Guan, X. Sun et al., "HSV-1 activates NF-kappaB in mouse astrocytes and increases TNF-alpha and IL-6 expression via Toll-like receptor 3," Neurological Research, vol. 35, no. 7, pp. 755-762, 2013.

[94] A. Casrouge, S.-Y. Zhang, C. Eidenschenk et al., "Herpes simplex virus encephalitis in human UNC-93B deficiency," Science, vol. 314, no. 5797, pp. 308-312, 2006.

[95] S.-Y. Zhang, E. Jouanguy, S. Ugolini et al., "TLR3 deficiency in patients with herpes simplex encephalitis," Science, vol. 317, no. 5844, pp. 1522-1527, 2007.

[96] Y. Guo, M. Audry, M. Ciancanelli et al., "Herpes simplex virus encephalitis in a patient with complete TLR3 deficiency: TLR3 is otherwise redundant in protective immunity," Journal of Experimental Medicine, vol. 208, no. 10, pp. 2083-2098, 2011.

[97] F. G. Lafaille, I. M. Pessach, S.-Y. Zhang et al., "Impaired intrinsic immunity to HSV-1 in human iPSC-derived TLR3deficient CNS cells," Nature, vol. 491, no. 7426, pp. 769-773, 2012.

[98] A. A. Ashkar, X.-D. Yao, N. Gill, D. Sajic, A. J. Patrick, and K. L. Rosenthal, "Toll-like receptor (TLR)-3, but not TLR4, agonist protects against genital herpes infection in the absence of inflammation seen with CpG DNA," The Journal of Infectious Diseases, vol. 190, no. 10, pp. 1841-1849, 2004.

[99] R. L. Miller, L. M. Imbertson, M. J. Reiter, and J. F. Gerster, "Treatment of primary herpes simplex virus infection in guinea pigs by imiquimod," Antiviral Research, vol. 44, no. 1, pp. 31-42, 1999.

[100] D. Hirokawa, A. Woldow, S. N. Lee, and F. Samie, "Treatment of recalcitrant herpes simplex virus with topical imiquimod," Cutis, vol. 88, no. 6, pp. 276-277, 2011.

[101] Y. Kan, T. Okabayashi, S.-I. Yokota, S. Yamamoto, N. Fujii, and T. Yamashita, "Imiquimod suppresses propagation of herpes simplex virus 1 by upregulation of cystatin a via the adenosine receptor Al pathway," Journal of Virology, vol. 86, no. 19, pp. 10338-10346, 2012.

[102] A.-S. Lascaux, E. Caumes, C. Deback et al., "Successful treatment of aciclovir and foscarnet resistant Herpes simplex virus lesions with topical imiquimod in patients infected with human immunodeficiency virus type 1," Journal of Medical Virology, vol. 84, no. 2, pp. 194-197, 2012.

[103] N. Boivin, R. Menasria, J. Piret, and G. Boivin, "Modulation of TLR9 response in a mouse model of herpes simplex virus encephalitis," Antiviral Research, vol. 96, no. 3, pp. 414-421, 2012.
[104] H. Shen and A. Iwasaki, "A crucial role for plasmacytoid dendritic cells in antiviral protection by CpG ODN-based vaginal microbicide," The Journal of Clinical Investigation, vol. 116, no. 8, pp. 2237-2243, 2006.

[105] A. M. Harandi, K. Eriksson, and J. Holmgren, "A protective role of locally administered immunostimulatory $\mathrm{CpG}$ oligodeoxynucleotide in a mouse model of genital herpes infection," Journal of Virology, vol. 77, no. 2, pp. 953-962, 2003.

[106] R. B. Pyles, D. Higgins, C. Chalk et al., "Use of immunostimulatory sequence-containing oligonucleotides as topical therapy for genital herpes simplex virus type 2 infection," Journal of Virology, vol. 76, no. 22, pp. 11387-11396, 2002.

[107] M. M. Sauter, J. J. L. Gauger, and C. R. Brandt, "Oligonucleotides designed to inhibit TLR9 block herpes simplex virus type 1 infection at multiple steps," Antiviral Research, vol. 109, pp. 8396, 2014

[108] R. B. Pyles, D. Higgins, C. Chalk et al., "Use of immunostimulatory sequence-containing oligonucleotides as topical therapy for genital herpes simplex virus type 2 infection," Journal of Virology, vol. 76, no. 22, pp. 11387-11396, 2002.

[109] N. Boivin, R. Menasria, J. Piret, S. Rivest, and G. Boivin, “The combination of valacyclovir with an anti-TNF alpha antibody increases survival rate compared to antiviral therapy alone in a murine model of herpes simplex virus encephalitis," Antiviral Research, vol. 100, no. 3, pp. 649-653, 2013.

[110] K. Triantafilou, D. Eryilmazlar, and M. Triantafilou, "Herpes simplex virus 2 -induced activation in vaginal cells involves Tolllike receptors 2 and 9 and DNA sensors DAI and IFI16," The American Journal of Obstetrics and Gynecology, vol. 210, no. 2, pp. 122.e1-122.e10, 2014.

[111] T. Gianni and G. Campadelli-Fiume, “ $\alpha \mathrm{v} \beta 3$-integrin relocalizes nectinl and routes herpes simplex virus to lipid rafts," Journal of Virology, vol. 86, no. 5, pp. 2850-2855, 2012.

[112] C. D. Conrady, M. Zheng, K. A. Fitzgerald, C. Liu, and D. J. J. Carr, "Resistance to HSV-1 infection in the epithelium resides with the novel innate sensor, IFI-16," Mucosal Immunology, vol. 5, no. 2, pp. 173-183, 2012.

[113] L. Unterholzner, S. E. Keating, M. Baran et al., "IFI16 is an innate immune sensor for intracellular DNA," Nature Immunology, vol. 11, no. 11, pp. 997-1004, 2010.

[114] K. E. Johnson, V. Bottero, S. Flaherty et al., "IFI16 restricts HSV1 replication by accumulating on the HSV-1 genome, repressing HSV-1 gene expression, and directly or indirectly modulating histone modifications," PLoS Pathogens, vol. 10, no. 11, Article ID e1004503, 2014.

[115] X.-D. Li, J. Wu, D. Gao, H. Wang, L. Sun, and Z. J. Chen, "Pivotal roles of cGAS-cGAMP signaling in antiviral defense and immune adjuvant effects," Science, vol. 341, no. 6152, pp. 1390-1394, 2013

[116] X.-D. Yao and K. L. Rosenthal, "Herpes simplex virus type 2 virion host shutoff protein suppresses innate dsRNA antiviral pathways in human vaginal epithelial cells," Journal of General Virology, vol. 92, part 9, pp. 1981-1993, 2011.

[117] K. E. Johnson, L. Chikoti, and B. Chandran, "Herpes simplex virus 1 infection induces activation and subsequent inhibition of the IFI16 and NLRP3 inflammasomes," Journal of Virology, vol. 87, no. 9, pp. 5005-5018, 2013.

[118] G. Zhou, V. Galvan, G. Campadelli-Fiume, and B. Roizman, "Glycoprotein D or J delivered in trans blocks apoptosis in SK$\mathrm{N}$-SH cells induced by a herpes simplex virus 1 mutant lacking intact genes expressing both glycoproteins," Journal of Virology, vol. 74, no. 24, pp. 11782-11791, 2000. 
[119] Y. Yamauchi, T. Daikoku, F. Goshima, and Y. Nishiyama, "Herpes simplex virus UL14 protein blocks apoptosis," Microbiology and Immunology, vol. 47, no. 9, pp. 685-689, 2003.

[120] E. K. Golembewski, S. Q. Wales, L. Aurelian, and P. J. Yarowsky, "The HSV-2 protein ICP10PK prevents neuronal apoptosis and loss of function in an in vivo model of neurodegeneration associated with glutamate excitotoxicity," Experimental Neurology, vol. 203, no. 2, pp. 381-393, 2007.

[121] D. Perkins, E. F. R. Pereira, M. Gober, P. J. Yarowsky, and L. Aurelian, "The herpes simplex virus type $2 \mathrm{rl}$ protein kinase (ICP10 PK) blocks apoptosis in hippocampal neurons, involving activation of the MEK/MAPK survival pathway," Journal of Virology, vol. 76, no. 3, pp. 1435-1449, 2002.

[122] X. Wang, C. Patenode, and B. Roizman, " $U_{S} 3$ protein kinase of HSV-1 cycles between the cytoplasm and nucleus and interacts with programmed cell death protein 4 (PDCD4) to block apoptosis," Proceedings of the National Academy of Sciences of the United States of America, vol. 108, no. 35, pp. 14632-14636, 2011.

[123] X. Wang, Y. Li, S. Liu et al., "Direct activation of RIP3/MLKLdependent necrosis by herpes simplex virus 1 (HSV-1) protein ICP6 triggers host antiviral defense," Proceedings of the National Academy of Sciences of the United States of America, vol. 111, no. 43, pp. 15438-15443, 2014.

[124] A. Iannello, O. Debbeche, R. El Arabi et al., "Herpes simplex virus type 1-induced FasL expression in human monocytic cells and its implications for cell death, viral replication, and immune evasion," Viral Immunology, vol. 24, no. 1, pp. 11-26, 2011.

[125] L. Bosnjak, M. Miranda-Saksena, D. M. Koelle, R. A. Boadle, C. A. Jones, and A. L. Cunningham, "Herpes simplex virus infection of human dendritic cells induces apoptosis and allows cross-presentation via uninfected dendritic cells," Journal of Immunology, vol. 174, no. 4, pp. 2220-2227, 2005.

[126] M. Stefanidou, I. Ramos, V. M. Casullo et al., "Herpes simplex virus 2 (HSV-2) prevents dendritic cell maturation, induces apoptosis, and triggers release of proinflammatory cytokines: Potential links to HSV-HIV synergy," Journal of Virology, vol. 87, no. 3, pp. 1443-1453, 2013.

[127] P. A. M. Gobeil and D. A. Leib, "Herpes simplex virus gamma34.5 interferes with autophagosome maturation and antigen presentation in dendritic cells," MBio, vol. 3, no. 5, pp. e00267-e00212, 2012.

[128] B. Yordy, N. Iijima, A. Huttner, D. Leib, and A. Iwasaki, "A neuron-specific role for autophagy in antiviral defense against herpes simplex virus," Cell Host and Microbe, vol. 12, no. 3, pp. 334-345, 2012.

[129] D. J. J. Carr, L. Tomanek, R. H. Silverman, I. L. Campbell, and B. R. G. Williams, "RNA-dependent protein kinase is required for alpha-1 interferon transgene-induced resistance to genital herpes simplex virus type 2," Journal of Virology, vol. 79, no. 14, pp. 9341-9345, 2005.

[130] D. A. Leib, M. A. Machalek, B. R. G. Williams, R. H. Silverman, and H. W. Virgin, "Specific phenotypic restoration of an attenuated virus by knockout of a host resistance gene," Proceedings of the National Academy of Sciences of the United States of America, vol. 97, no. 11, pp. 6097-6101, 2000.

[131] B. He, M. Gross, and B. Roizman, "The $\gamma 134.5$ protein of herpes simplex virus 1 complexes with protein phosphatase $1 \alpha$ to dephosphorylate the $\alpha$ subunit of the eukaryotic translation initiation factor 2 and preclude the shutoff of protein synthesis by double-stranded RNA-activated protein kinase," Proceedings of the National Academy of Sciences of the United States of America, vol. 94, no. 3, pp. 843-848, 1997.

[132] J. Poppers, M. Mulvey, D. Khoo, and I. Mohr, "Inhibition of PKR activation by the proline-rich RNA binding domain of the herpes simplex virus type 1 Us11 protein," Journal of Virology, vol. 74, no. 23, pp. 11215-11221, 2000.

[133] M. Shu, B. Taddeo, W. Zhang, and B. Roizman, "Selective degradation of mRNAs by the HSV host shutoff RNase is regulated by the UL47 tegument protein," Proceedings of the National Academy of Sciences of the United States of America, vol. 110, no. 18, pp. E1669-E1675, 2013.

[134] B. Taddeo, W. Zhang, and B. Roizman, "The Herpes Simplex Virus host shutoff RNase degrades cellular and viral mRNAs made before infection but not viral mRNA made after infection," Journal of Virology, vol. 87, no. 8, pp. 4516-4522, 2013.

[135] D. K. Kaushik, M. Gupta, and A. Basu, "Microglial response to viral challenges: every silver lining comes with a cloud," Frontiers in Bioscience, vol. 16, no. 6, pp. 2187-2205, 2011.

[136] G. N. Milligan and D. I. Bernstein, "Interferon- $\gamma$ enhances resolution of herpes simplex virus type 2 infection of the murine genital tract," Virology, vol. 229, no. 1, pp. 259-268, 1997.

[137] T. Peng, J. Zhu, A. Klock et al., "Evasion of the mucosal innate immune system by herpes simplex virus type 2," Journal of Virology, vol. 83, no. 23, pp. 12559-12568, 2009.

[138] G. D. Luker, J. L. Prior, J. Song, C. M. Pica, and D. A. Leib, "Bioluminescence imaging reveals systemic dissemination of herpes simplex virus type 1 in the absence of interferon receptors," Journal of Virology, vol. 77, no. 20, pp. 11082-11093, 2003.

[139] K. E. Johnson, B. Song, and D. M. Knipe, "Role for herpes simplex virus 1 ICP27 in the inhibition of type I interferon signaling," Virology, vol. 374, no. 2, pp. 487-494, 2008.

[140] S. Wang, K. Wang, R. Lin, and C. Zheng, "Herpes simplex virus 1 serine/threonine kinase US3 hyperphosphorylates IRF3 and inhibits beta interferon production," Journal of Virology, vol. 87, no. 23, pp. 12814-12827, 2013.

[141] J. Xing, L. Ni, S. Wang, K. Wang, R. Lin, and C. Zheng, "Herpes simplex virus 1-encoded tegument protein VP16 abrogates the production of beta interferon (IFN) by inhibiting NF-kappaB activation and blocking IFN regulatory factor 3 to recruit its coactivator CBP," Journal of Virology, vol. 87, no. 17, pp. 97889801, 2013.

[142] S. Wang, K. Wang, J. Li, and C. Zhenga, "Herpes simplex virus 1 ubiquitin-specific protease UL36 inhibits beta interferon production by deubiquitinating TRAF3," Journal of Virology, vol. 87, no. 21, pp. 11851-11860, 2013.

[143] J. Shupack, M. Stiller, I. Davis, C. Kenny, and L. Jondreau, “Topical alpha-interferon ointment with dimethyl sulfoxide in the treatment of recurrent genital herpes simplex," Dermatology, vol. 184, no. 1, pp. 40-44, 1992.

[144] K. Y. Fung, N. E. Mangan, H. Cumming et al., "Interferon- $\varepsilon$ protects the female reproductive tract from viral and bacterial infection," Science, vol. 339, no. 6123, pp. 1088-1092, 2013.

[145] P. Hermant, C. Francius, F. Clotman, and T. Michiels, "IFNepsilon is constitutively expressed by cells of the reproductive tract and is inefficiently secreted by fibroblasts and cell lines," PLoS ONE, vol. 8, no. 8, Article ID e71320, 2013.

[146] N. E. Mangan, N. Bourke, C. Gargett, and P. J. Hertzog, "125: a role for interferon epsilon in the innate immune response in the female reproductive tract," Cytokine, vol. 70, no. 1, 58 pages, 2014. 
[147] H. Li, J. Zhang, A. Kumar, M. Zheng, S. S. Atherton, and F.-S. $\mathrm{X}$. Yu, "Herpes simplex virus 1 infection induces the expression of proinflammatory cytokines, interferons and TLR7 in human corneal epithelial cells," Immunology, vol. 117, no. 2, pp. 167-176, 2006.

[148] T. H. Mogensen and S. R. Paludan, "Molecular pathways in virus-induced cytokine production," Microbiology and Molecular Biology Reviews, vol. 65, no. 1, pp. 131-150, 2001.

[149] J. Zhang, S. Wang, K. Wang, and C. Zheng, "Herpes simplex virus 1 DNA polymerase processivity factor UL42 inhibits TNF$\alpha$-induced NF- $\kappa \mathrm{B}$ activation by interacting with p65/RelA and p50/NF- $\kappa$ B1," Medical Microbiology and Immunology, vol. 202, no. 4, pp. 313-325, 2013.

[150] J. Zhang, K. Wang, S. Wang, and C. Zheng, "Herpes simplex virus $1 \mathrm{E} 3$ ubiquitin ligase ICP0 protein inhibits tumor necrosis factor alpha-induced NF-kappaB activation by interacting with p65/RelA and p50/NF-kappaB1," Journal of Virology, vol. 87, no. 23, pp. 12935-12948, 2013.

[151] K. Wang, L. Ni, S. Wang, and C. Zheng, "Herpes simplex virus 1 protein kinase US3 hyperphosphorylates p65/RelA and dampens NF-kappaB activation," Journal of Virology, vol. 88, no. 14, pp. 7941-7951, 2014.

[152] X. Liu, K. Fitzgerald, E. Kurt-Jones, R. Finberg, and D. M. Knipe, "Herpesvirus tegument protein activates NF- $\kappa$ B signaling through the TRAF6 adaptor protein," Proceedings of the National Academy of Sciences of the United States of America, vol. 105, no. 32, pp. 11335-11339, 2008.

[153] A. Patel, J. Hanson, T. I. McLean et al., "Herpes simplex virus type 1 induction of persistent NF- $\kappa \mathrm{B}$ nuclear translocation increases the efficiency of virus replication," Virology, vol. 247, no. 2, pp. 212-222, 1998.

[154] D. Gregory, D. Hargett, D. Holmes, E. Money, and S. L. Bachenheimer, "Efficient replication by herpes simplex virus type 1 involves activation of the I $\kappa \mathrm{B}$ kinase-I $\kappa \mathrm{B}-\mathrm{p} 65$ pathway," Journal of Virology, vol. 78, no. 24, pp. 13582-13590, 2004.

[155] V. H. Ferreira, A. Nazli, K. L. Mossman, and C. Kaushic, "Proinflammatory cytokines and chemokines-but not interferonbeta-produced in response to HSV-2 in primary human genital epithelial cells are associated with viral replication and the presence of the virion host shutoff protein," The American Journal of Reproductive Immunology, vol. 70, no. 3, pp. 199-212, 2013.

[156] W. Huang, K. Hu, S. Luo et al., "Herpes simplex virus type 2 infection of human epithelial cells induces CXCL9 expression and $\mathrm{CD} 4^{+} \mathrm{T}$ cell migration via activation of $\mathrm{p} 38$ CCAAT/enhancer-binding protein- $\beta$ pathway," The Journal of Immunology, vol. 188, no. 12, pp. 6247-6257, 2012.

[157] M. Thapa, R. S. Welner, R. Pelayo, and D. J. J. Carr, "CXCL9 and CXCL10 expression are critical for control of genital herpes simplex virus type 2 infection through mobilization of HSVspecific CTL and NK cells to the nervous system," Journal of Immunology, vol. 180, no. 2, pp. 1098-1106, 2008.

[158] H. Shin and A. Iwasaki, "A vaccine strategy that protects against genital herpes by establishing local memory T cells," Nature, vol. 491, no. 7424, pp. 463-467, 2012.

[159] C. D. Conrady, M. Zheng, N. A. Mandal, N. Van Rooijen, and D. J. J. Carr, "IFN-alpha-driven CCL2 production recruits inflammatory monocytes to infection site in mice," Mucosal Immunology, vol. 6, no. 1, pp. 45-55, 2013.
[160] C. D. Conrady, M. Zheng, N. van Rooijen et al., "Microglia and a functional type i IFN pathway are required to counter HSV-1driven brain lateral ventricle enlargement and encephalitis," The Journal of Immunology, vol. 190, no. 6, pp. 2807-2817, 2013.

[161] A. J. Chucair-Elliott, C. Conrady, M. Zheng, C. M. Kroll, T. E. Lane, and D. J. J. Carr, "Microglia-induced IL-6 protects against neuronal loss following HSV-1 infection of neural progenitor cells," Glia, vol. 62, no. 9, pp. 1418-1434, 2014.

[162] R. Aoki, T. Kawamura, F. Goshima et al., "Mast cells play a key role in host defense against herpes simplex virus infection through TNF- $\alpha$ and IL-6 production," Journal of Investigative Dermatology, vol. 133, no. 9, pp. 2170-2179, 2013.

[163] L. Corey, A. Wald, C. L. Celum, and T. C. Quinn, “The effects of herpes simplex virus- 2 on HIV-1 acquisition and transmission: a review of two overlapping epidemics," Journal of Acquired Immune Deficiency Syndromes, vol. 35, no. 5, pp. 435-445, 2004.

[164] K. E. Johnson, A. D. Redd, T. C. Quinn et al., "Effects of HIV-1 and herpes simplex virus type 2 infection on lymphocyte and dendritic cell density in adult foreskins from Rakai, Uganda," Journal of Infectious Diseases, vol. 203, no. 5, pp. 602-609, 2011.

[165] A. Rebbapragada, C. Wachihi, C. Pettengell et al., "Negative mucosal synergy between Herpes simplex type 2 and HIV in the female genital tract," AIDS, vol. 21, no. 5, pp. 589-598, 2007.

[166] E. Sartori, A. Calistri, C. Salata, C. del Vecchio, G. Pal, and C. Parolin, "Herpes simplex virus type 2 infection increases human immunodeficiency virus type 1 entry into human primary macrophages," Virology Journal, vol. 8, article 166, 2011.

[167] E. Martinelli, H. Tharinger, I. Frank et al., "HSV-2 infection of dendritic cells amplifies a highly susceptible HIV-1 cell target," PLoS Pathogens, vol. 7, no. 6, Article ID e1002109, 2011.

[168] M. A. W. P. de Jong, L. de Witte, M. E. Taylor, and T. B. H. Geijtenbeek, "Herpes simplex virus type 2 enhances HIV-1 susceptibility by affecting langerhans cell function," The Journal of Immunology, vol. 185, no. 3, pp. 1633-1641, 2010.

[169] E. Fakioglu, S. S. Wilson, P. M. M. Mesquita et al., "Herpes simplex virus downregulates secretory leukocyte protease inhibitor: a novel immune evasion mechanism," Journal of Virology, vol. 82, no. 19, pp. 9337-9344, 2008.

[170] A. T. Stock, J. M. Smith, and F. R. Carbone, "Type I IFN suppresses Cxcr2 driven neutrophil recruitment into the sensory ganglia during viral infection," Journal of Experimental Medicine, vol. 211, no. 5, pp. 751-759, 2014.

[171] J. M. Lubinski, M. Jiang, L. Hook et al., "Herpes simplex virus type 1 evades the effects of antibody and complement in vivo," Journal of Virology, vol. 76, no. 18, pp. 9232-9241, 2002.

[172] W. P. Halford, J. L. Maender, and B. M. Gebhardt, "Re-evaluating the role of natural killer cells in innate resistance to herpes simplex virus type 1," Virology Journal, vol. 2, article 56, 2005.

[173] S. Nandakumar, S. N. Woolard, D. Yuan, B. T. Rouse, and U. Kumaraguru, "Natural killer cells as novel helpers in anti-herpes simplex virus immune response," Journal of Virology, vol. 82, no. 21, pp. 10820-10831, 2008.

[174] M. Kim, N. R. Osborne, W. Zeng et al., "Herpes simplex virus antigens directly activate NK cells via TLR2, thus facilitating their presentation to CD4 T lymphocytes," The Journal of Immunology, vol. 188, no. 9, pp. 4158-4170, 2012.

[175] D. Schepis, M. D’Amato, M. Studahl, T. Bergström, K. Kärre, and L. Berg, "Herpes simplex virus infection downmodulates NKG2D ligand expression," Scandinavian Journal of Immunology, vol. 69, no. 5, pp. 429-436, 2009. 
[176] R. Tomazin, A. B. Hill, P. Jugovic et al., "Stable binding of the herpes simplex virus ICP47 protein to the peptide binding site of TAP," The EMBO Journal, vol. 15, no. 13, pp. 3256-3266, 1996.

[177] D. I. Godfrey, D. G. Pellicci, O. Patel, L. Kjer-Nielsen, J. McCluskey, and J. Rossjohn, "Antigen recognition by CD1drestricted NKT T cell receptors," Seminars in Immunology, vol. 22, no. 2, pp. 61-67, 2010.

[178] L. Novakova, Z. Nevoralova, and J. Novak, "Innate-like behavior of human invariant natural killer $\mathrm{T}$ cells during herpes simplex virus infection," Cellular Immunology, vol. 278, no. 1-2, pp. 1620, 2012.

[179] P. Rao, H. T. Pham, A. Kulkarni et al., "Herpes simplex virus 1 Glycoprotein B and US3 collaborate to inhibit CD1d antigen presentation and NKT Cell function," Journal of Virology, vol. 85, no. 16, pp. 8093-8104, 2011.

[180] W. Yuan, A. Dasgupta, and P. Cresswell, "Herpes simplex virus evades natural killer $\mathrm{T}$ cell recognition by suppressing CD1d recycling," Nature Immunology, vol. 7, no. 8, pp. 835-842, 2006. 


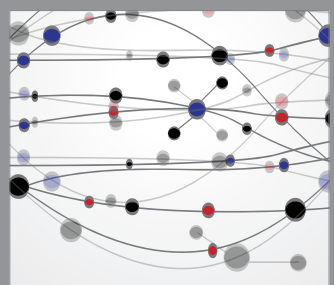

The Scientific World Journal
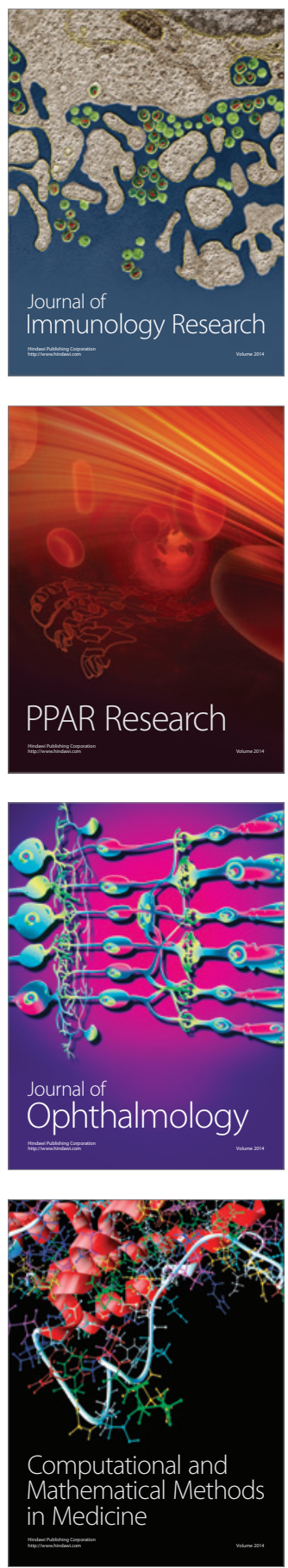

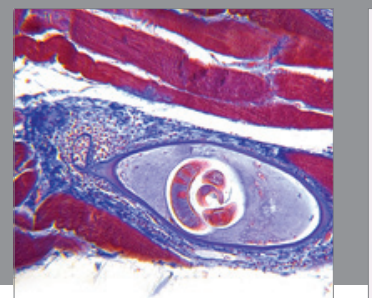

Gastroenterology

Research and Practice
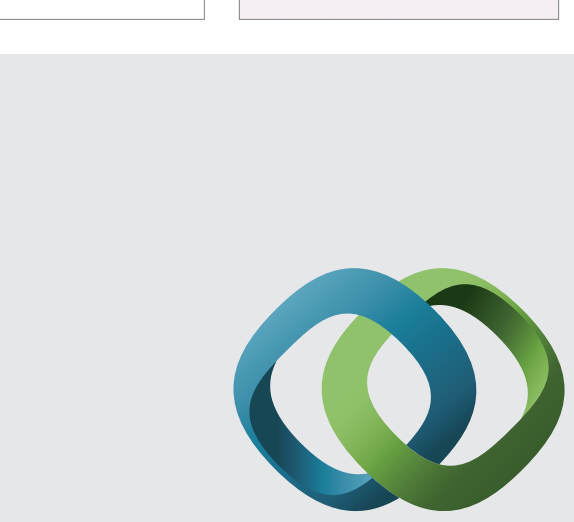

\section{Hindawi}

Submit your manuscripts at

http://www.hindawi.com
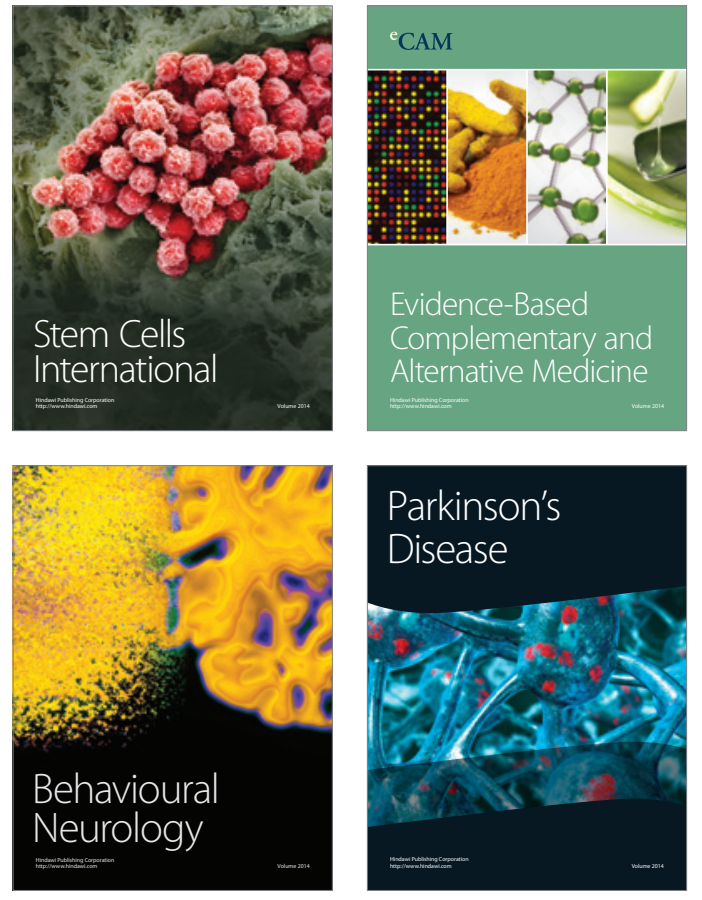
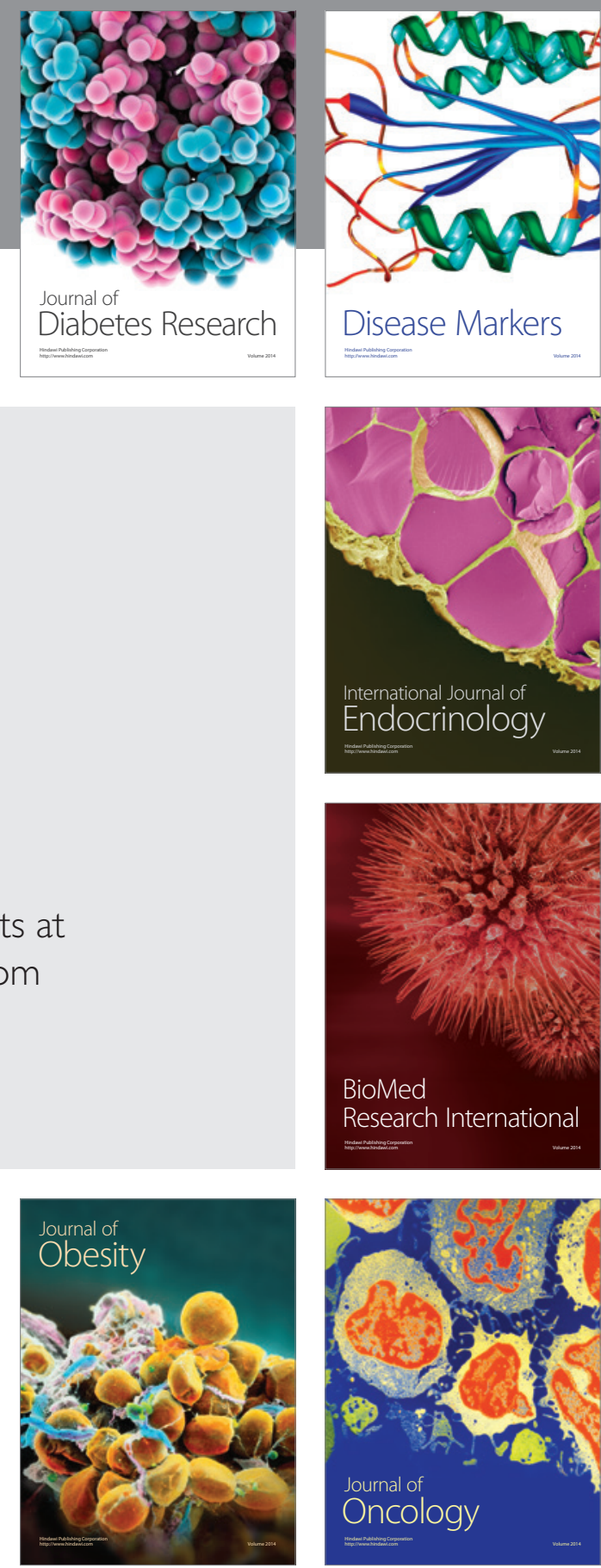

Disease Markers
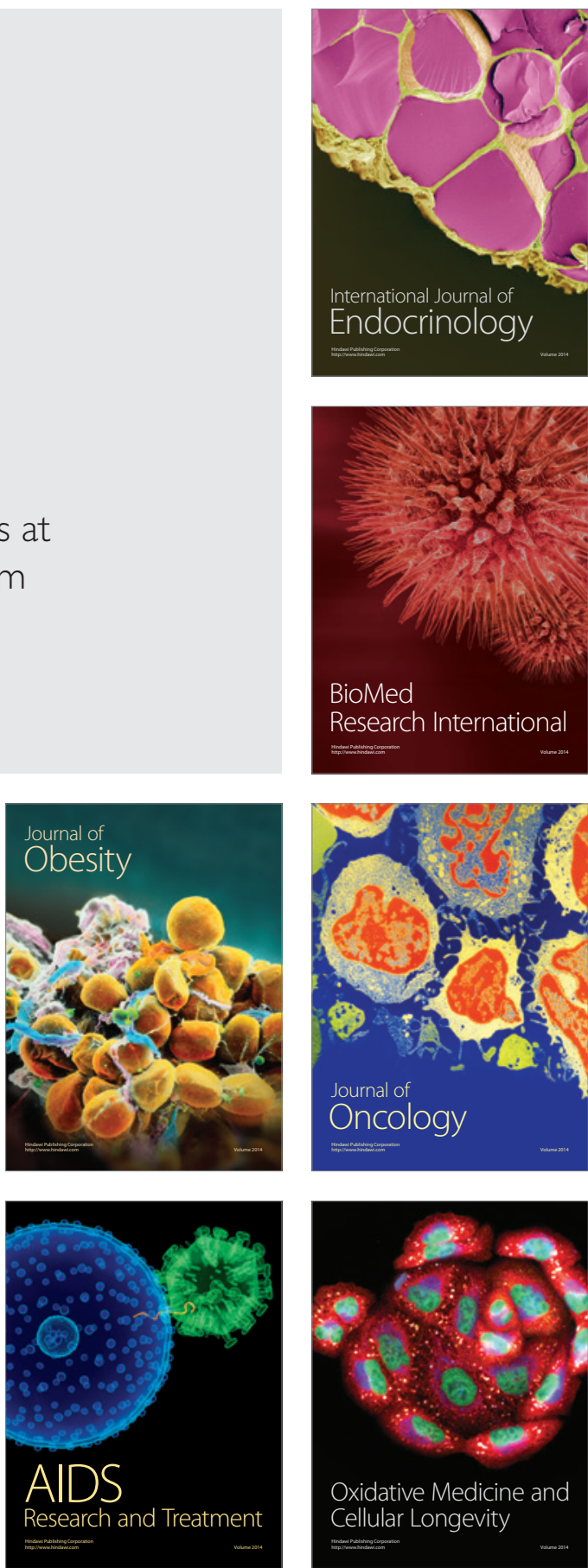